\title{
Xây dựng hệ tiêu chí đánh giá chính sách thúc đẩy khởi nghiệp trong bối cảnh toàn cầu hóa
}

\author{
Hoàng Thị Hải Yến* \\ Trường Đại học Khoa học Xã hội và Nhân văn, ĐHQGHN, 336 Nguyễn Trãi, Hà Nội, Việt Nam \\ Nhận ngày 9 tháng 8 năm 2017 \\ Chỉnh sửa ngày 14 tháng 9 năm 2017; Chấp nhận đăng ngày 28 tháng 9 năm 2017
}

\begin{abstract}
Tóm tắt: Bài viết này bước đầu đưa ra các cơ sở lý luận dựa trên đặc điểm và các yêu cầu của chính sách thúc đẩy khởi nghiệp trong bối cảnh toàn cầu hóa, từ đó xây dựng hệ tiêu chí đánh giá loại chính sách này. Hệ tiêu chí này có thể được sử dụng để tiến hành đánh giá chính sách thúc đẩy khởi nghiệp trong bối cảnh toàn cầu hóa, vận dụng vào đánh giá chính sách ở Việt Nam và đưa ra các gợi ý hoàn thiện chính sách.
\end{abstract}

Tù khóa: Khởi nghiệp, chính sách thúc đẩy khởi nghiệp, toàn cầu hóa, hệ tiêu chí đánh giá.

\section{Dẫn nhập}

Khái niệm khởi nghiệp được chú ý từ năm đầu những năm 2000 ở Việt Nam, có những chuyển biến mạnh về các hoạt động liên quan tới khởi nghiệp khoảng từ năm 2005, nhưng chỉ thực sự có những dấu mốc đột phá quan trọng trong chính sách thúc đẩy khởi nghiệp sáng tạo khoảng từ năm 2010 trở lại đây. Manh nha từ Nghị định 80/NĐ-CP về Doanh nghiệp Khoa học và Công nghệ (năm 2007), nhưng phải tới sau 2010, Việt Nam mới có những chính sách cụ thể hơn dành cho các đối tượng khởi nghiệp sáng tạo với các dấu mốc rất đáng chú ý: Năm 2013: Bộ Khoa học và Công nghệ khởi động Đề án thương mại hóa công nghệ với mô hình thung lũng Silicon tại Việt Nam, năm 2015: diễn ra sự kiện Khởi nghiẹp đổi mới sáng tạo Techfest do Bộ Khoa học và Công nghệ tổ chức với quy mô toàn quốc, năm 2016: ra đời Nghị

\footnotetext{
*ĐT.: 84-983268135.

Email: yenvict@gmail.com

https://doi.org/10.25073/2588-1116/vnupam.4122
}

quyết 35 về hỗ trợ và phát triển doanh nghiệp tới năm 2020 (trong đó có doanh nghiẹp khởi nghiệp), Đề án hệ sinh thái khởi nghiệp đổi mới sáng tạo quốc gia đến năm 2025 (Đề án 844), năm 2017: ra đời Luật hỗ trợ doanh nghiệp nhỏ và vừa (trong đó có hỗ trợ doanh nghiệp nhỏ và vừa khởi nghiệp sáng tạo).

Khởi nghiệp ở Việt Nam không thể tách rời bối cảnh hội nhập quốc tế và các tác động mạnh mẽ của cuộc cách mạng công nghiệp 4.0. Việc xem xét, đánh giá các chính sách thúc đẩy khởi nghiệp ở Việt Nam là điều rất quan trọng để từ đó có thể điều chỉnh và hoàn thiện chính sách.

Chính vì lẽ đó, bài viết này bước đầu đưa ra các cơ sở lý luận dựa trên đặc điểm và các yêu cầu của chính sách thúc đầy khởi nghiệp trong bối cảnh toàn cầu hóa, từ đó xây dựng hệ tiêu chí đánh giá loại chính sách này. Hệ tiêu chí này có thể được sử dụng để tiến hành đánh giá chính sách thúc đẩy khởi nghiệp trong bối cảnh toàn cầu hóa, vận dụng vào đánh giá chính sách ở Việt Nam và đưa ra các gợi ý hoàn thiện chính sách. 


\section{Vai trò quan trọng của chính sách thúc đẩy khởi nghiệp trong bối cảnh toàn cầu hóa}

Chính sách thúc đẩy khởi nghiệp là một tập hợp biện pháp được thể chế hoá, mà một chủ thể quyền lực, hoặc chủ thể quản lý đưa ra, trong đó tạo sự ưu đãi cho các doanh nghiệp khởi nghiệp, kích thích vào động cơ hoạt động của nhóm này, định hướng hoạt động của họ nhằm phát triển các hoạt động khởi nghiệp mang lại các lợi ích kinh tế chung cho bản thân doanh nghiệp và cộng đồng.

Trên thực tế, có thể tiến hành khởi nghiệp thông qua nhiều cách (mở cửa hàng kinh doanh, đi làm thuê, gửi tiền vào ngân hàng hưởng lãi,...) mà trong đó bao gồm cả cách không cần tới sức lực của trí tuệ hay bất kỳ một sự sáng tạo nào. Tuy nhiên, bài viết này không hướng tới mọi loại hoạt động khởi nghiệp như vậy mà thuật ngữ khởi nghiệp ở đây ám chỉ tới một cách làm trong khởi nghiệp - đó là, khởi nghiệp mang tính sáng tạo hay nói cách khác là có hàm lượng khoa học, công nghệ trong hoạt động khởi nghiệp. Nghĩa là, trong khi "khởi nghiẹp (thông thuờng)" là khái niệm chỉ việc bắt đầu tạo dựng công việc, sự nghiệp riêng thì "khởi nghiệp (sáng tạo)" (trong tiếng Anh dùng thuật ngữ "startup" hay "start-up") là một trong những loại hình, cách thức mà người ta có thể lựa chọn để "khởi nghiệp", được xem như một dạng thức kinh doanh mới (new business model) và đặt ra một yêu cầu rất quan trọng là: tạo ra cái mới (mới có thể về công nghệ, mới về sản phẩm, mới về dịch vu hay mới về cách làm, cách đưa sản phẩm/dịch vu ra thi truò̀ng, ...)/tìm cách giải quyết một vấn đề mới (do đó cần sủ dụng các giải pháp mói thông qua vận dụng các kết quả của nghiên cúu khoa họ, công nghệ hay với cách làm mói).

Có thể tóm gọn sự khác biệt giữa khởi nghiệp thông thường và khởi nghiệp sáng tạo như sau:

Bảng 1. Sự khác biệt giữa khởi nghiệp thông thường và khởi nghiệp sáng tạo

\begin{tabular}{|c|c|c|}
\hline Điểm so sánh & Khởi nghiệp thông thường & Khởi nghiệp sáng tạo (startup) \\
\hline Loại hình & Mô hình kinh doanh thông thường & Mô hình kinh doanh sáng tạo \\
\hline Điểm bắt đầu & $\begin{array}{l}\text { Bất kỳ một ý tưởng nào có thể đem lại } \\
\text { lợi nhuận }\end{array}$ & Ý tưởng sáng tạo \\
\hline Người sáng lập & $\begin{array}{l}\text { Thường là cá nhân độc lập/tách ra từ } \\
\text { một tập đoàn hay công ty lớn }\end{array}$ & $\begin{array}{l}\text { Thường là một nhóm người đang đi } \\
\text { tìm kiếm một mô hình kinh doanh } \\
\text { mới }\end{array}$ \\
\hline Yếu tố tạo khác biệt & $\begin{array}{l}\text { Không nhất thiết cần tới kiến thức của } \\
\text { khoa học, công nghệ và đổi mới }\end{array}$ & $\begin{array}{l}\text { Dựa trên khoa học, công nghệ và đổi } \\
\text { mới }\end{array}$ \\
\hline Mục tiêu ưu tiên & Lợi nhuận & Tăng trưởng nhanh \\
\hline Định hướng đầu ra & $\begin{array}{l}\text { Lợi nhuận } \\
\text { Có thể không tạo ra sản phẩm } \\
\text { mới/công nghệ mới/cách sử dụng mới }\end{array}$ & $\begin{array}{l}\text { Tạo ra sản phẩm mới/công nghệ } \\
\text { mới/cách sử dụng mới }\end{array}$ \\
\hline Đặc điểm & $\begin{array}{l}\text { Chắc chắn } \\
\text { Do thị truòng sã̃n có, đã lự chọn được } \\
\text { phuơng án kinh doanh an toàn }\end{array}$ & 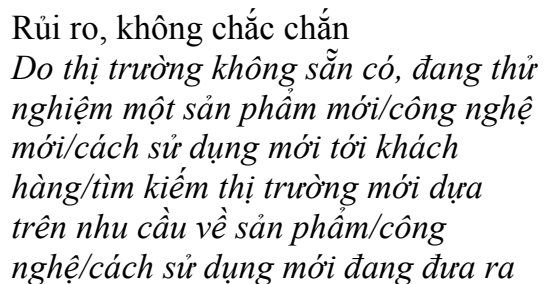 \\
\hline Quy mô & Có thể là quy mô lớn/nhỏ & $\begin{array}{l}\text { Thường bắt đầu là quy mô nhỏ nhưng } \\
\text { hướng tới quy mô toàn cầu }\end{array}$ \\
\hline Điểm kết thúc & $\begin{array}{l}\text { Không nhất thiết tạo ra được } 1 \text { doanh } \\
\text { nghiệp }\end{array}$ & $\begin{array}{l}\text { Một doanh nghiệp được niêm yết trên } \\
\text { sàn chứng khoán (IPO) }\end{array}$ \\
\hline
\end{tabular}


Do đó, để thúc đẩy khởi nghiệp sáng tạo trong bối cảnh toàn cầu hóa, cần có chính sách với các đặc điểm riêng biệt có khả năng cung cấp các nguồn lực (trí lực, nhân lực, tài lực, tin $l u ̛ c, \ldots$ ) đáp ứng được nhu cầu của đối tượng khởi nghiệp này.

Để giải quyết điều này, tác giả đã sử dụng 3 lý thuyết: $L y ́$ thuyết đổi mói, $L y$ thuyết hệ thổng và Lý thuyết toàn cầu hóa nhằm phân tích và chỉ ra các điểm khác biệt cơ bản của chính sách thúc đẩy khởi nghiệp sáng tạo trong bối cảnh toàn cầu hóa như sau:

\subsection{Nhìn nhận doanh nghiệp khởi nghiệp nhu là một trung tâm đổi mới}

Lý thuyết đổi mới cho thấy các doanh nghiệp khởi nghiệp sáng tạo đóng vai trò trung chuyển ý tưởng sáng tạo tới thị trường, giống như các doanh nghiệp đổi mới (Innovative firm) - được hiểu là doanh nghiệp trong đó thực hiện ít nhất một hoạt động đổi mới [1].

Mối quan hệ này được thể hiện thông qua Mô hình xây dựng các doanh nghiệp dựa trên các thể chế Khoa học, Công nghệ và Kỹ thuật (gọi tắt là SET) hướng tới phát triển kinh tế của Essegbey 2008 được nghiên cứu trích dẫn như sau:

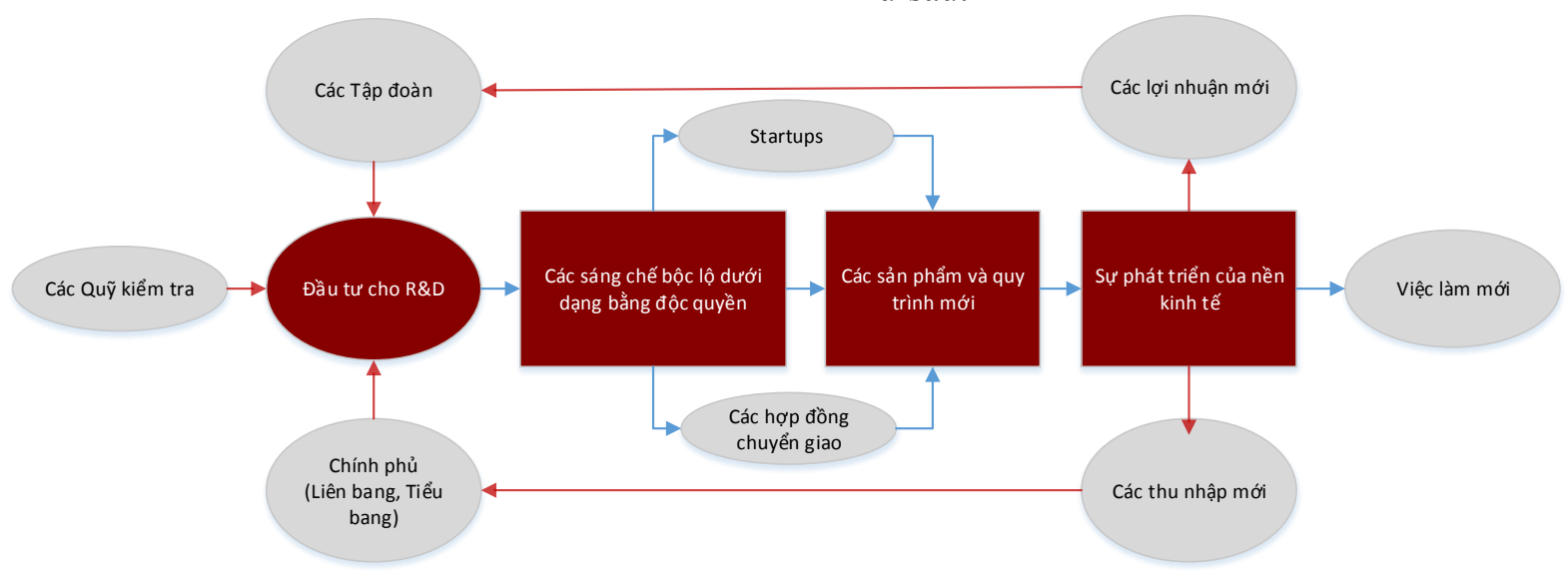

Hình 1. Mô hình xây dựng các doanh nghiệp dựa trên SET [2].

Essegbey đã cho thấy vai trò của các doanh nghiệp khởi nghiệp (startups) trong việc thương mại hóa kết quả từ khu vực nghiên cứu và triển khai $(R \& D)$ tới thị trường thông qua việc biến đổi sáng chế - có được thông qua chuyển giao bằng độc quyền sáng - thành sản phẩm và quy trình mới (new products and processes), từ đó thúc đẩy nền kinh tế phát triển.

Jongtaik Lee và đồng nghiệp 2016 đã làm rõ hơn vai trò của các doanh nghiệp khởi nghiệp như một thành tố chính trong quá trình thương mại hóa công nghệ. Doanh nghiệp khởi nghiệp được tác giả gọi là một "Trung tâm đổi mói i" (Innovation Center) cùng với các tổ chức chuyển giao công nghệ $(T L O)$, các vườn ươm doanh nghiệp, các tổ chức thúc đẩy doanh nghiệp (Incubator, Accelerator) và các nhà đầu tư cho đổi mới (Investor). Đáng lưu ý, nghiên cứu đã đưa ra được một sơ đồ cho sự tương tác và các dòng chuyển hóa tri thức, công nghệ giữa các thành tố thành khi tham gia hệ sinh thái đổi mới (Innovation Ecosystem). Mối quan hệ giữa các trung tâm đổi mới này với các bên liên quan (có 04 thành tố chính gồm: nhà nghiên cứu - Researchers, các tổ chức tài chính cho đổi mới - Innovation Capitalists, các doanh nghiệp lớn - Large Firms và các nguồn lực từ cộng đồng - Community Resources (như các chương trình tài trợ của chính phủ - State Funded Programs, người hướng dẫn kinh doanh và kỹ thuật - Business and Technical Mentors,...) được Jongtaik Lee và đồng nghiệp mô tả dưới dạng sơ đồ hóa dưới đây: 


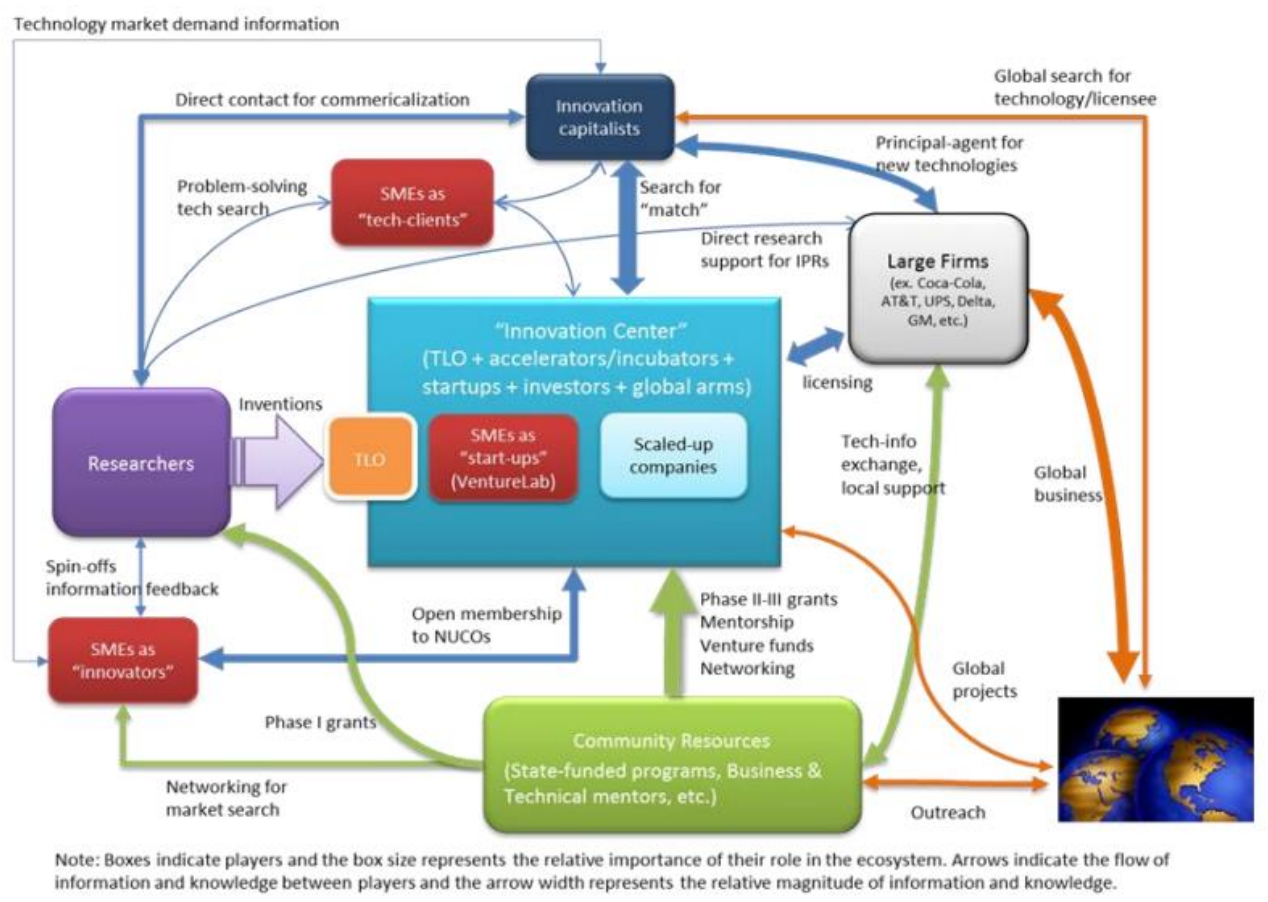

Hình 2. Mô hình đa nền tảng trong mạng lưới thương mại hóa công nghệ [3].

Qua sơ đồ, có thể thấy để trở thành một trung tâm đổi mới, các startup luôn bắt đầu từ nghiên cứu khoa học với 3 con đường chính:

- Tự tìm kiếm, đề xuất các giải pháp công nghệ từ nhu cầu của mình (khi đó, startup đóng vai trò là các khách hàng công nghệ - Techclients)

- Nhận chuyển giao công nghệ thông qua các tổ chức chuyển giao $(T L O)$ (khi đó, startups đóng vai trò như các phòng thí nghiệm mạo hiểm - VentureLabs)

- Đưa ra các cải tiến thông qua các thông tin phản hồi của khách hàng (khi đó, startup đóng vai trò là các nhà đổi mới - Innovators)

Do đó, chính sách thúc đẩy khởi nghiệp cần lưu ý tới các yếu tố hình thành năng lực đổi mới của các doanh nghiệp khởi nghiệp trong việc hình thành chính sách thúc đầy như: Văn hóa (những hỗ trợ từ doanh nghiệp cho đổi mới), các nguồn lực (tài chính, vật chất, con người, trí tuệ), Năng lục (những khả năng phát triển cho đổi mới), và Mang lưới liên kết (bao gồm các khách hàng, nhà cung cấp, đối thủ cạnh tranh, và quan hệ đối tác với các viện nghiên cứu và các trường đại học) [4]. Nghiên cứu của StartupAUS 2016 [5] chỉ rõ thêm các kỹ năng cần thiết đối với một đổi mới hiện đại thúc đầy nền kinh tế bao gồm:

- Kỹ năng kinh doanh và tinh thần kinh thương;

- Kỹ năng công nghệ; và

- Kỹ năng nghiên cứu khoa học.

Những kỹ năng này rất quan trọng bởi vì họ là cần thiết để hỗ trợ cốt lõi của hệ thống đổi mới. Nghiên cứu của StartupAUS 2016 cũng đã nhấn mạnh vai trò của các chính sách chính phủ và các trường đại học trong việc tạo ra các nguồn nhân lực có đầy đủ các kỹ năng đáp ứng đổi mới này. Theo nghiên cứu, các nước đã đạt được những thành công ở mức độ cao của tinh thần doanh thương và năng lực kỹ thuật thường có các chính sách chính phủ trong việc hỗ trợ mạnh mẽ một hệ sinh thái khởi nghiệp. Việc bắt đầu sớm là quan trọng với việc giảng dạy các kỹ năng như mã hóa tài liệu kỹ thuật số và tinh thần doanh thương trong các trường học. Các 
nền kinh tế đổi mới hàng đầu cũng có xu hướng công nhận vai trò của các trường đại học như người điều khiển của cả tiến bộ công nghệ và văn hóa kinh doanh.

\subsection{Dẫn dắt và Định huớng để doanh nghiệp} khởi nghiệp tiên phong trong việc giải quyết các vấn đề của xã hội mà không phải doanh nghiệp nào cũng muốn và đủ khả năng xủ lý

Trong xã hội đang xuất hiện quá nhiều vấn đề như thành phố ô nhiễm, sự béo phì, chăm sóc sức khỏe, tiếp cận giáo dục, cung ứng nước sạch,...nhưng đáng buồn là số lượng các công nghệ được tạo ra trong các hệ sinh thái khởi nghiệp dẫn đầu trên thế giới mới chỉ là dừng lại ở tầm nhìn ngắn hạn và tập trung vào các vấn đề lợi nhuận hơn là giải quyết những vấn đề lớn và cơ bản như vậy [6]. Các tác giả kêu gọi việc tập trung vào đổi mới đối với các vấn đề thực sự đang tồn tại xung quanh mà con người và xã hội đang phải đối mặt trên khắp thế giới, trong đó, các doanh nghiệp khởi nghiệp cần là những người tiên phong.

Thêm vào đó, các nghiên cứu về đổi mới chỉ ra rằng, có sự dịch chuyển lớn giữa hệ sinh thái đổi mới (Innovation Ecosystem) sang hệ sinh thái khởi nghiệp sáng tạo (Startup Ecosystem) bởi lẽ hệ sinh thái khởi nghiệp sáng tạo không chỉ mang đầy đủ các đặc điểm của hệ sinh thái đổi mới mà còn mang các yếu tố mở hơn, có khả năng đem lại hiệu quả cao hơn trong đổi mới. Mô hình về xu hướng lớn mang tính toàn cầu trong các hệ sinh thái (Global Megatrend in Ecosystems) của Startup Commons đưa ra có thể cho thấy rõ hơn sự dịch chuyển này. Theo đó, vị trí trung tâm của đổi mới trước đây là các công ty lớn và khu vực công (Big Companies \& Public Sector) với các nguồn lực nội tại và quy trình đóng kín thì nay chuyển sang các doanh nghiệp khởi nghiệp (Startups) với các nguồn lực từ bên ngoài, hợp tác và cởi mở. Hệ sinh thái khởi nghiệp không chỉ nhấn mạnh vai trò trung tâm của các startups mà còn bổ sung các thành tố trong hệ sinh thái so với các thành tố vốn tồn tại (các kết quả nghiên cứu khoa học, các nguồn lực đầu tư, khách hàng) trong hệ sinh thái đổi mới là: các giải pháp tài chính mới (New Funding Solutions), các tổ chức hỗ trợ (Support Organizations) và các nhà cung cấp dịch vụ (Service Providers).

\section{Innovation}

Ecosystem

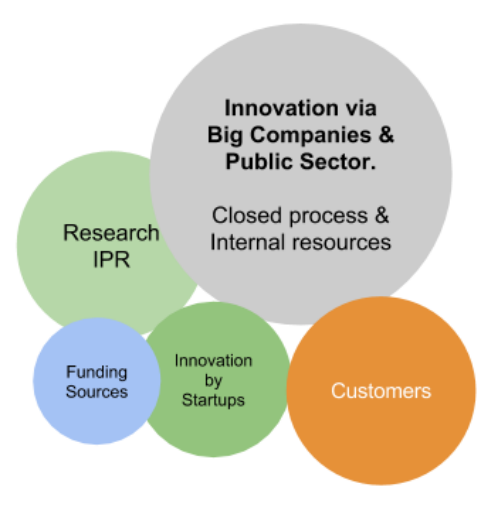

Startup

Ecosystem

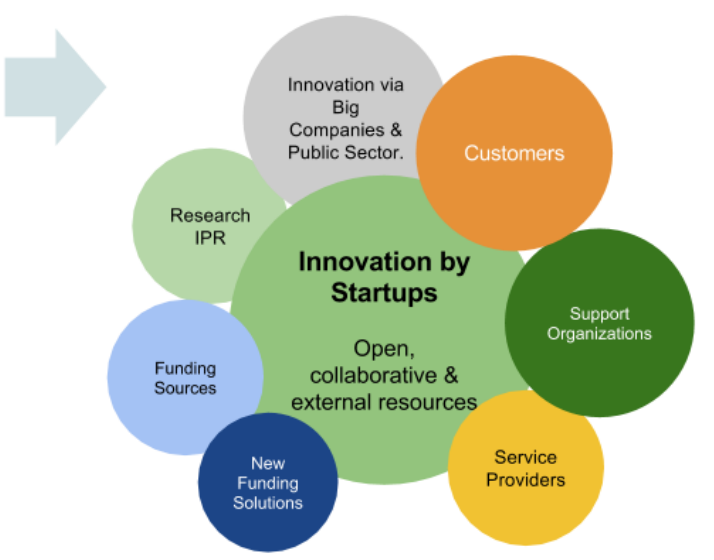

Hình 3. Xu hướng lớn mang tính toàn cầu trong các hệ sinh thái [7]. 
Đây chính là một bài toán của các nhà hoạch định chính sách khi vừa tác động được vào động cơ của doanh nghiệp khởi nghiệp, vừa định hướng được các doanh nghiệp này phục vụ mục tiêu của nhà quản lý: xử lý các vấn đề lớn của xã hội thông qua các hoạt động đổi mới của doanh nghiệp, thực hiện sứ mệnh của mình là trung tâm của đổi mới.

2.3. Doanh nghiệp khởi nghiệp không tồn tại độc lập mà cần một hệ sinh thái để tồn tại
Lý thuyết hệ thống cho thấy cần nhìn nhận bản thân các doanh nghiệp khởi nghiệp là một hệ thống (có mục tiêu và các phần tử tương tác trong nội bộ hệ thống) nhưng đồng thời là một phần tử trong hệ thống lớn hơn, trong đó có tương tác với các phần tử khác của hệ thống như các trường đại học, các trung tâm nghiên cứu, các doanh nghiệp khác,... trong quá trình biến đổi đầu vào (Input) thành đầu ra (Output) để thực hiện mục tiêu của mình và luôn xét tới môi trường hệ thống gồm cả môi trường quốc gia và quốc tế. Có thể hình dung các mối quan hệ này như sau:

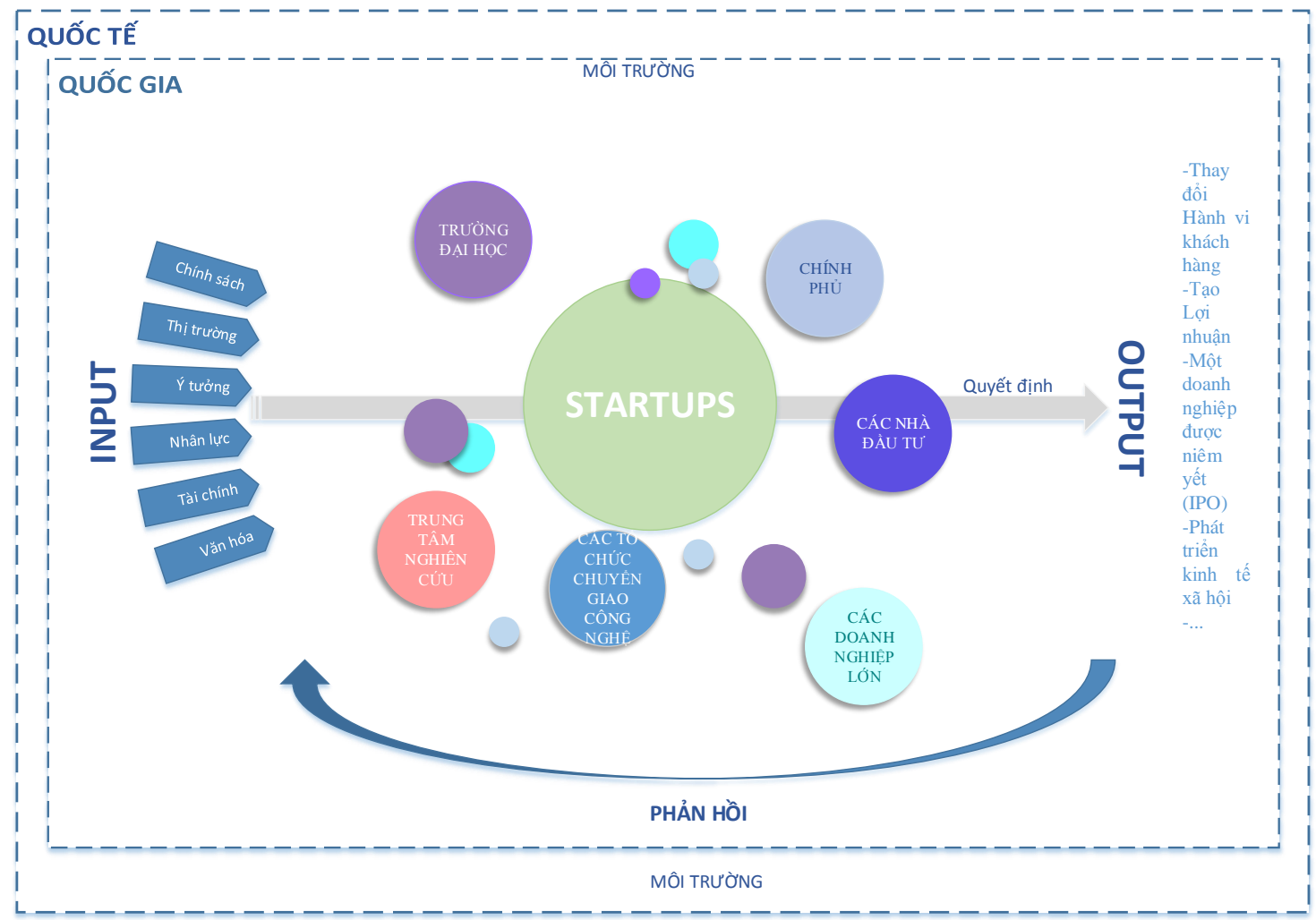

Hình 4. Tiếp cận hệ thống trong nghiên cứu về startups (Nguồn: Tác giả tổng hợp).

Các tiếp cận hệ thống trong nghiên cứu đề xuất chính sách thúc đẩy khởi nghiệp chỉ dẫn có thể thông qua tác động vào một/một số các yếu tố sau của hệ thống:

- Mục tiêu của hệ thống

- Các phần tử trong hệ thống
- Các môđun ${ }^{1}$ trong hệ thống

- Môi trường của hệ thống

\footnotetext{
${ }^{1}$ Môđun là một tập hợp con các phần tử nằm trong tập hợp các phần tử của hệ thống, thực hiện một chức năng cấu thành của hệ thống.
} 
Ngày nay, các khái niệm của sinh học hệ thống như "hệ sinh thái" (Ecosystem) được vận dụng một cách linh hoạt đối với các hệ thống khác của xã hội nhằm nhấn mạnh tính tương tác hữu cơ giữa các phần tử và môi trường - các phần tử trong hệ thống - được xem như một cơ thể sống. Do đó, khi nói "hệ sinh thái khởi nghiệp" thay vì chỉ nhìn nhận nó như một hệ thống thông thường là nghiên cứu ngụ ý đến môi trường sống, quan tâm tới những tương tác của môi trường sống này đã ảnh hưởng tới đối tượng nghiên cứu (startups) ra sao.

Hệ sinh thái khởi nghiệp là tổng hợp các mối liên kết chính thức và phi chính thức giữa các tác nhân khởi nghiệp (tiềm năng hoặc hiện tại), tổ chức khởi nghiệp (công ty, nhà đầu tư mạo hiểm, nhà đầu tư thiên thần, hệ thống ngân hàng,...) và các cơ quan liên quan (trường đại học, các cơ quan nhà nước, các quỹ đầu tư công,...) và tiến trình khởi nghiệp (tỉ lệ thành lập doanh nghiệp, số lượng doanh nghiệp có tỉ lệ tăng trưởng tốt, số lượng các nhà khởi nghiệp,...) tác động trực tiếp đến môi trường khởi nghiệp tại địa phương [8] hay được xem như cách thức một quốc gia hay một thành phố thiết lập để thúc đẩy hoạt động khởi nghiệp tại địa phương [9].

Như vậy, chính sách thúc đẩy khởi nghiệp cần tạo lập được một hệ sinh thái đáp ứng hai điều kiện:

- Tồn tại các điều kiện, môi trường trong đó các cá nhân, tổ chức, doanh nghiệp và xã hội đến với nhau để thúc đẩy sự thịnh vượng và phồn vinh của nền kinh tế;

- Diễn ra sự tương tác giữa các bên tổ chức liên quan và các cá nhân nhằm thúc đẩy tinh thần kinh doanh, đổi mới và tăng trưởng doanh nghiệp.

\subsection{Doanh nghiệp khởi nghiệp luôn định hướng toàn cầu và chịu các tác động tù̀ toàn cầu hóa}

Các lý thuyết về "toàn cầu hóa" (Globalization) bắt đầu được bàn nhiều trong các cuộc tranh luận những năm 1990 xét từ khía cạnh kinh tế [10]. Đây cũng là thời điểm mà khái niệm "nền kinh tế tri thức" được nổi lên [11]. Các đặc trưng của nền kinh tế này với quá trình toàn cầu hóa đã có những tương tác mang tính thúc đẩy lẫn nhau như: "xã hội thông tin" (Information society), "xã hội học hỏi" (Learning society), "các mạng lưới tri thức" (knowledge networks) và các hệ thống đổi mới quốc gia (National innovation systems), các doanh nghiệp sáng tạo (Innovating firms)...

Dù chưa có bất kỳ một nghiên cứu nào chỉ ra cụ thể các tác động của toàn cầu hóa tới doanh nghiệp khởi nghiệp, tuy nhiên, một cách gián tiếp, khi đây thực chất là một loại hình doanh nghiệp sáng tạo, có thể thấy rõ rằng loại hình này chịu tác động lớn bởi các đặc điểm của bối cảnh toàn cầu hóa. Các khảo sát được tiến hành đối với các doanh nghiệp khởi nghiệp (cả doanh nghiệp khởi nghiệp dựa trên công nghệ mới và công nghệ truyền thống) được thực hiện bởi Trung tâm nghiên cứu thương mại quốc tế về công nghệ, Viện Ngoại thương Ẩn Độ 2007 [12] cho thấy đa số người được hỏi cho biết doanh số của họ đã bị ảnh hưởng do thay đổi trong nhu cầu thị trường vì toàn cầu hóa nhanh chóng. Hầu hết các doanh nghiệp đã đa dạng hoặc thay đổi sản phẩm của họ, đồng thời sữ dụng các biện pháp cắt giảm chi phí để điều chỉnh nhu cầu thị trường phát sinh do những thay đổi gần đây trong môi trường bên ngoài vì việc gia tăng toàn cầu hóa dẫn đến cạnh tranh lớn hơn. Thêm vào đó, toàn cầu hóa cũng tạo một xu hướng mà doanh nghiệp khởi nghiệp có những thay đổi để phù hợp với "tiêu chuẩn quốc tế" để có cả cạnh tranh tại địa phương và trên toàn cầu.

Một trong những đặc trưng của doanh nghiệp khởi nghiệp là tăng trưởng nhanh định hướng toàn cầu nên tư duy xuất khẩu hay toàn cầu hóa là xu hướng đương nhiên của loại hình này. Do đó, việc nghiên cứu các tác động từ toàn cầu hóa tới các doanh nghiệp khởi nghiệp này là điều vô cùng quan trọng trong hoạch định chính sách thúc đẩy khởi nghiệp. 


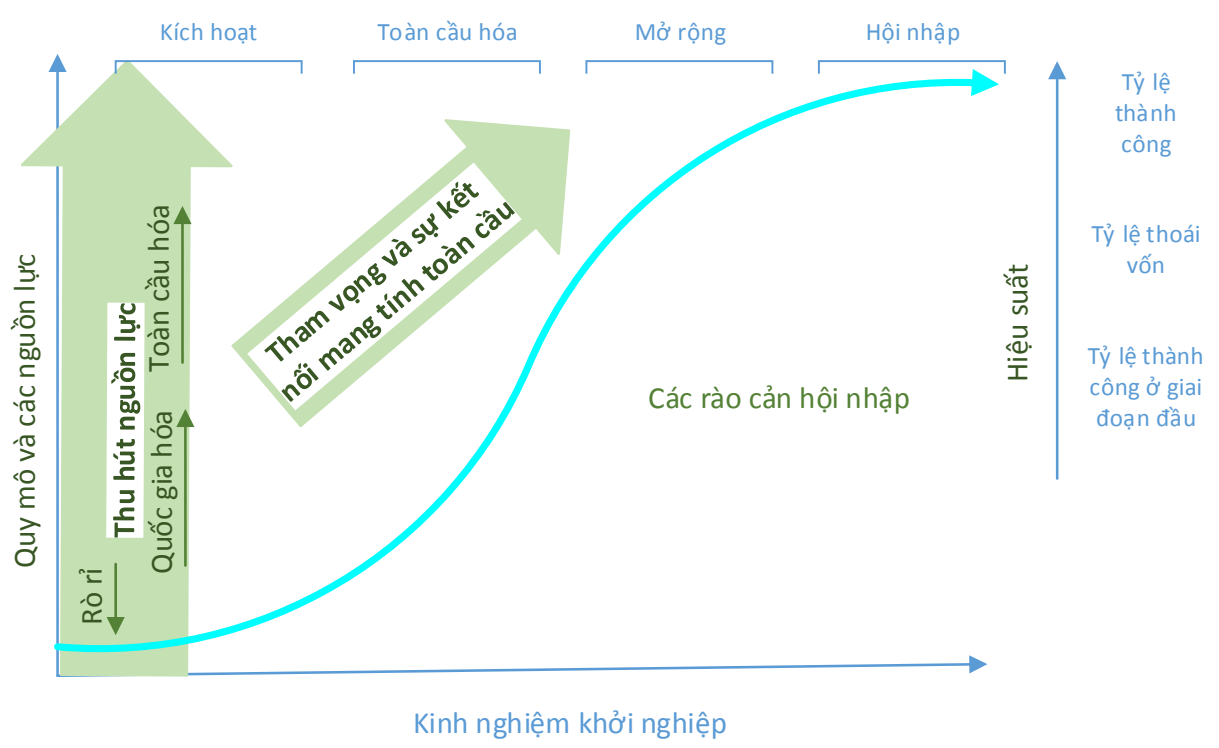

Hình 5. Mô hình vòng đời hệ sinh thái khởi nghiệp [13].

Thông qua các nghiên cứu về toàn cầu hóa, có thể thấy quá trình này mang lại cả thời cơ và thách thức đối với sự tồn tại và phát triển của các doanh nghiệp khởi nghiệp, trong đó đáng lưu ý có những đặc điểm lớn có khả năng tác động như sau:

1. Hợp tác xuyên biên giới.

- Di động của cộng đồng khoa học và thúc đẩy hợp tác trong KH\&CN.

- Gia tăng chuyển giao công nghệ.

- Tăng khả năng tiếp cận các nguồn đầu tư và tăng lựa chọn đầu tư (đặc biệt là các hình thức tài chính mới như đầu tư mạo hiểm, đầu tư thiên thần, gọi vốn cộng đồng,...)

2. Cung cấp thị trường rộng lớn và tiềm năng.

3. Thách thức từ các tập đoàn đa quốc gia.

4. Sự trỗi dậy của làn sóng khởi nghiệp sáng tạo và nhu cầu về hệ sinh thái khởi nghiệp toàn cầu.

Chính sách thúc đẩy khởi nghiệp trong bối cảnh toàn cầu hóa cần giúp các doanh nghiệp khởi nghiệp khai thác được các cơ hội tới từ toàn cầu hóa, giảm thiểu được các rào cản để hội nhập quốc tế thành công.

\section{Sự cần thiết đánh giá chính sách để thúc đẩy khởi nghiệp hiệu quả}

Chính sách thúc đẩy có một vai trò vô cùng quan trọng đối với đạt mục tiêu của bản thân nhà hoạch định chính sách lẫn đối tượng thụ hưởng chính sách. Về lý luận, chính sách là một công cự của quản lý. Về thực tiễn, các nghiền cứu về chính sách của các quốc gia đã chỉ ra rằng chính sách thường được xem là vấn đề lớn nhất mà các doanh nghiệp khởi nghiệp gặp phải [14] và chính sách giúp gia tăng số lượng và chất lượng của các doanh nghiệp mới với những người có đam mê khởi nghiệp và giúp đỡ họ vượt qua các rào cản họ phải đối mặt [15]. Các hình thức mới trong hợp tác giữa khu vực nhà nước và khu vực tư nhân và khu vực học thuật đang tạo ra môi trường liên kết mạnh cho các cơ hội đối với các doanh nghiệp dựa trên KH\&CN như doanh nghiệp khởi nghiệp, thông qua việc thiết kế các chính sách đổi mới, các công cụ và phương thức thực thi chính sách [16].

Các nghiên cứu ở Việt Nam khi bàn về các rào cản đối với doanh nghiệp khởi nghiệp ở Việt Nam cũng chỉ ra rằng sự bất cập của chính sách nhà nước là một trong những rào cản lớn nhất. Để hỗ trợ cho các doanh nghiệp khởi 
nghiệp thì vai trò của Nhà nước là vô cùng quan trọng, cụ thể như: Chia sẻ những rủi ro trong hoạt động đầu tư mạo hiểm; Tham gia vào hoạt động đầu tư mạo hiểm cho các lĩnh vực khoa học và công nghệ có thể mang lại nhiều lợi ích cho xã hội và kinh tế quốc gia như công nghệ sinh học, vật liệu mới,... Hỗ trợ vốn mồi cho doanh nghiệp trong giai đoạn đầu (early stage), có thể bằng cách trực tiếp đầu tư, tài trợ hoặc đối ứng đầu tư với các nhà đầu tư thiên thần và các quỹ đầu tư cho giai đoạn đầu; Hỗ trợ, đầu tư cho các hoạt động đào tạo, tập huấn khởi nghiệp, nhất là tại các trường đại học; Kết nối các thành phần của hệ sinh thái khởi nghiệp thành một mạng lưới [17].

Như vậy, hầu hết các nghiên cứu đề cập vấn đề này đều cho rằng các doanh nghiệp khởi nghiệp cần được xem xét và cải tiến quy định và khuôn khổ pháp lý để khuyến khích sự tăng trưởng và khả năng cạnh tranh của các doanh nghiệp khởi nghiệp, hay nói cách khác, chính phủ nên tiến hành các cải cách phù hợp, hiệu quả, cấp thiết để hỗ trợ doanh nghiệp cả về nhận thức, vốn, khả năng hợp tác và tiếp cận công nghệ,...Thay đổi về các thiết chế của chính phủ cũng như nhân viên chính phủ đáp ứng nhu cầu thiết yếu của doanh nghiệp dựa trên công nghệ là điều đang được các doanh nghiệp khởi nghiệp kỳ vọng.

Do đó, muốn đạt được kỳ vọng về sự tăng trưởng doanh nghiệp khởi nghiệp cả về chất lượng và số lượng, chính sách thúc đẩy khởi nghiệp sáng tạo đóng một vai trò rất quan trọng, đòi hỏi nhà hoạch định chính sách thường xuyên xem xét, đánh giá để khớp được các biện pháp thúc đẩy với nhu cầu của đối tượng chính sách, nhằm tạo ra hiệu quả cao nhất có thể. Việc hành động hay không hành động của chính sách sẽ ảnh hưởng đến việc thúc đẩy hay không thúc đẩy, thậm chí là kìm hãm khởi nghiệp. Đánh giá chính sách thúc đẩy khởi nghiệp trong bối cảnh toàn cầu hóa lại càng đặt ra cấp bách đối với Việt Nam khi hoạt động khởi nghiệp cũng như hoạch định chính sách cho khởi nghiệp mới đang ở giai đoạn đầu, trong khi Việt Nam đang trong tiến trình hội nhập quốc tế sâu rộng.
Đánh giá chính sách có thể được tiến hành ở bất cứ giai đoạn nào trong chu trình chính sách bởi "Đánh giá chính sách là xem xét chính sách tù nhiều góc độ khác nhau, phát hiện điểm mạn, điểm yểu của chính sách để phục vu cho các muc đích sử dụng khác nhau” [18].

Hiện nay, dù lý thuyết cũng thực tiễn về đánh giá chính sách đã được nhiều nghiên cứu bàn thảo sâu nhưng chưa có nghiên cứu nào đề cập cơ sở lý luận với khung đánh giá cụ thể đối với đánh giá chính sách thúc đẩy khởi nghiệp. Các nghiên cứu quốc tế cũng như các nghiên cứu Việt Nam mới bước đầu đưa ra những phân tích, đánh giá hoạt động khởi nghiệp nói chung, trong đó, việc liên hệ tới chính sách chỉ để lý giải các kết quả đạt được/chưa đạt được của khởi nghiệp $[19,20]$ (đáng lưu ý có báo cáo Chỉ số khởi nghiệp - $\mathrm{GEM}^{2}$ toàn cầu và GEM Việt Nam hằng năm). Điều này cho thấy các nghiên cứu đến nay chưa quan tâm đúng mức tới đánh giá chính sách thúc đẩy khởi nghiệp.

Chính vì vậy, việc đề xuất khung đánh giá với các tiêu chí đánh giá cụ thể để có thể tiến hành đánh giá các chính sách thúc đẩy khởi nghiệp trong bối cảnh toàn cầu hóa là mục tiêu quan trọng của bài viết này.

Tiêu chí (criterion) là các yêu cầu, chuẩn $m u c c$ được đề ra dùng để kiểm định hoặc để đánh giá một đối tượng. Các yêu cầu này thường quy định về chất lượng, mức độ, hiệu quả, khả năng, tuân thủ các qui tắc, các kết quả cuối cùng và tính bền vững của các kết quả đó. Trong một số trường hợp, Tiêu chí được hiểu là tính chất, dấu hiệu để dựa vào đó mà phân biệt một vật, một khái niệm, nhằm phê phán, hoặc đánh giá.

Hệ tiêu chí (criterion system) là tập hợp một số các tiêu chí nhằm tạo sự thống nhất trong đánh giá một đối tượng nào đó. Một đặc điểm

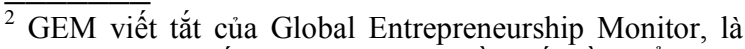
nghiên cứu Chỉ số khởi nghiệp toàn cầu, bắt đầu triển khai từ năm 1999. Sau 17 năm triển khai, GEM đã thu hút được khoảng 100 quốc gia tham dự và trở thành nghiên cứu có quy mô lớn nhất về khởi nghiệp trên toàn cầu. Năm 2015 là năm thứ ba liên tiếp Phòng Thương mại và Công nghiệp Việt Nam (VCCI) đại diện cho Việt Nam tham gia nghiên cứu GEM.
} 
cần quan tâm khi xây dựng Hệ tiêu chí, đó là mặc dù tiêu chí luôn phản ánh quan điểm của chủ thể đánh giá, nhưng cần đảm bảo tính khách quan, khoa học để việc đánh giá dựa trên hệ tiêu chí đã chọn phải góp phần thúc đẩy quá trình phát triển bền vững của đối tượng nói riêng, và của xã hội nói chung.

\section{4. Đề xuất hệ tiêu chí đánh giá chính sách thúc đẩy khởi nghiệp trong bối cảnh toàn cầu hóa}

\subsection{Co sở hình thành khung đánh giá}

Với các lý luận về đặc điểm của khởi nghiệp và các yêu cầu đối với chính sách thúc đẩy khởi nghiệp trong bối cảnh toàn cầu hóa như trên, có thể thấy điểm cốt lõi khi hình thành chính sách thúc đẩy khởi nghiệp sáng tạo là cần nhìn nhận doanh nghiệp khởi nghiệp như một cơ thể sống và cơ thể sống này chỉ sống khỏe nếu có được các nền tảng tốt và một môi trường sống tốt - đó chính là hệ sinh thái khởi nghiệp (startup ecosystem). Trong hệ sinh thái đó (xem hình 6 dưới đây), các doanh nghiệp khởi nghiệp đóng vai trò trung tâm, dẫn dắt và lãnh đạo (leaders) và các bên liên quan khác đóng vai trò hỗ trợ (feeders), bao gồm nhưng không giới hạn các tổ chức hỗ trợ, các tổ chức tài trợ vốn, các doanh nghiệp lớn, các trường đại học/viện nghiên cứu, các nhà cung cấp dịch vụ,... có mối quan hệ hữu cơ, cùng tồn tại và phát triển bền vững. Nhà nước có vai trò hỗ trợ (feeder), tạo dựng môi trường pháp lý (regulatory framework) hay gọi đơn giản là "luật choì" cho hệ sinh thái khởi nghiệp phát triển. Sức mạnh của hệ sinh thái khởi nghiệp tùy thuộc vào sự gắn kết chặt chẽ của các thành phần bền trong hệ sinh thái khởi nghiệp. Như vậy, muốn thúc đẩy doanh nghiệp khởi nghiệp phát triển, điều quan trọng nhất là Nhà nước cần đưa ra được các chính sách tạo dựng một hệ sinh thái khởi nghiệp khỏe mạnh và các chính sách đáp ứng đúng nhu cầu của doanh nghiệp khởi nghiệp sáng tạo.

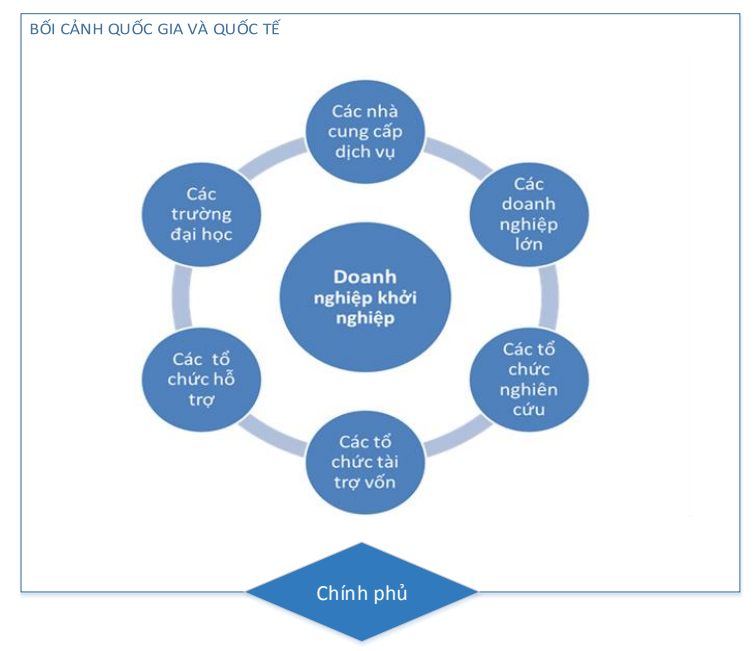

Hình 6. Các phần tử trong hệ sinh thái khởi nghiệp sáng tạo.

(Nguồn: Tác giả tổng hợp)

Thông qua tiếp cận từ lý thuyết đổi mới, lý thuyết hệ thống và lý thuyết toàn cầu hóa đưa tới cách tiếp cận trong xây dựng chính sách thúc đẩy khởi nghiệp trong bối cảnh toàn cầu hóa với ba điểm lưu ý chính:

- Kích thích các yếu tố để doanh nghiệp khởi nghiệp thực hiện được chức năng là một trung tâm đổi mới;

- Không tách rời doanh nghiệp khởi nghiệp trong tương tác với các phần tử khác của hệ thống và môi trường hệ thống;

- Bối cảnh toàn cầu hóa vừa là môi trường, vừa là đích tới quan trọng của doanh nghiệp khởi nghiệp, chứa đựng nhiều thời cơ nhưng cũng không ít thách thức.

Nhu cầu của doanh nghiệp khởi nghiệp ở mỗi giai đoạn phát triển khác nhau dẫn tới mức độ tham gia của các thành tố trong hệ sinh thái cũng khác nhau: 


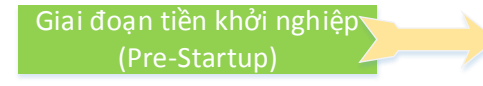

Giai đoạn khởi nghiệp

(Startup)

\begin{abstract}
- Tăng cường vốn (thông qua gia đình/bạn bè/quỹ đầu tư mạo hiểm/ nhà đầu tư thiên thần/nhân viên)

- Cung cấp thông tin (thông tin KH\&CN, thông tin nhu cầu thị trường,...thông qua các bên trung gian/tổ chức hỗ trợ)

- Hướng dẫn và hỗ trợ (thông qua người hướng dẫn là các chuyên gia về khởi nghiệp/doanh nghiệp lớn, các tổ chức hỗ trợ về pháp lý, kinh doanh, chuyển giao quyền sở hữu trí tuệ, mặt bằng, cơ sở vật chất,...)

- Chiến lược đầu tư/hợp tác (thông qua các doanh nghiệp lớn)

- Chiến lược mở rộng quy mô định

hướng toàn cầu (thông qua các tư vấn/chuyên gia/đối tác)

- Các ưu đãi từ chính phủ (ví dụ: ưu

đãi thuế,...)
\end{abstract}

- Thủ tục thành lập doanh nghiệp
Giai đoạn hậu khởi nghiệp (Post-Startup) (thông qua các tổ chức hỗ trợ kinh doanh)

Hình 7. Nhu cầu của doanh nghiệp khởi nghiệp qua các giai đoạn phát triển

(Nguồn: Tác giả tổng hợp)

Từ đó, các nội dung cơ bản cần có của chính sách thúc đẩy khởi nghiệp trong bối cảnh toàn cầu hóa có thể đưa ra để đánh giá như sau:

1) Khích lệ tinh thần sáng tạo và tinh thần kinh thuoong

2) Hố trợ doanh nghiệp khởi nghiệp (uom tạo, tài chính, thông tin, tư vấn và huớng dẫn, dịch vu hố trợ,...)

3) Kết nối các thành phần trong hệ sinh thái khởi nghiệp

4) Xóa bỏ các rào cản pháp lý và hành chính

5) Hội nhập thị trường quốc tế

\subsection{Hệ tiêu chí đánh giá}

4.2.1. Nhóm tiêu chí đánh giá khả năng khích lệ tinh thần sáng tạo và tinh thần kinh thuoong

Tinh thần sáng tạo và tinh thần kinh thương được xem là những yếu tố đầu tiên cần có trong văn hóa khởi nghiệp, thực chất là quyết định chất lượng của nguồn nhân lực khởi nghiệp.

\begin{abstract}
- Các điều kiện để mở rộng mang tính toàn cầu (thông tin về thị trường toàn cầu, kết nối các nguồn lực quốc tế, các chính sách khởi nghiệp toàn cầu như Visa Startup...thông qua các bên trung gian/tổ chức hỗ trợ, chính phủ)

- Các thủ tục thoái vốn (thông qua các quy định về thủ tục và điều kiện của chính phủ về phá sản, mua bán doanh nghiệp, định giá tài sản trí tuệ, niêm yết lần đầu sàn chứng khoán, chào hàng lần thứ hai,...)
\end{abstract}

Chính sách thúc đẩy khởi nghiệp cần tạo ra được đội ngũ nhân lực có tinh thần sáng tạo (có khả năng đua ra các ý tuởng sáng tạo, tạo ra các sáng chế) và tinh thần kinh thương (có khả năng đura các ý tuởng sáng tạo/sáng chế vào hoạt động thuơng mại để tạo ra đổi móti). Điều này có thể được thực hiện thông qua các chính sách giáo duc và đào tạo (xem xét chương trình đào tạo có các môn học phát triển tư duy sáng tạo như môn Phuoong pháp nghiên cúu khoa học, Phuoong pháp luận sáng tạo,... và phát triển tinh thần kinh thương như môn Luật kinh doanh, Các kỹ năng kinh doanh, văn hóa khởi nghiệp,...không, có các hoạt động nhằm nâng cao nhận thức về văn hoá kinh doanh không), chính sách khuyến khích nghiên cứu khoa học (Có chính sách khuyến khích sinh viên nghiên cứu khoa học trong trường đại học không, Có cơ sở vật chất (phòng thí nghiệm,...) thuận lợi để triển khai các nghiên cứu khoa học không,...), chính sách thuoong mại hóa kêt quả nghiên cúu và chính sách văn hóa khởi nghiệp. 


\subsubsection{Nhóm tiêu chí đánh giá khả năng hỗ trọ doanh nghiệp khởi nghiệp}

Như đã chỉ ra, doanh nghiệp khởi nghiệp là loại hình tổ chức rất cần các hỗ trợ để phát triển. Do đó, chính sách thúc đẩy cần được đánh giá trên các khía cạnh hỗ trợ như sau

- Chính sách về ươm tạo: chủ yếu thông qua các vườn ươm hay các tổ chức thúc đẩy kinh doanh.

- Chính sách tài chính: lấp đầy sự thiếu hụt về vốn của doanh nghiệp khởi nghiệp theo các giai đoạn phát triển, chủ yếu là loại hình vốn phi truyền thống như đầu tư mạo hiểm hay đầu tư thiên thần; các ưu đãi thuế; tạo thuận lợi trong việc tiếp cận các khoản vay thương mại,...

- Chính sách thông tin: phá bỏ lỗ hổng thông tin bất đối xứng của doanh nghiệp khởi nghiệp thông qua việc cung ứng các thông tin $\mathrm{KH} \& \mathrm{CN}$, thông tin về thị trường, thông tin về các bên liên quan,...

- Chính sách thị trường: tạo lập thị trường thuận lợi cho các doanh nghiệp khởi nghiệp phát triển ở cả hai khía cạnh khung khổ pháp lý và tạo nhu cầu thị truoòng, ví dụ: Kích hoạt nhu cầu thông qua các cuộc gọi thách thức và mua sắm công cho các doanh nghiệp khởi nghiệp)

- Chính sách về hệ thống hỗ trợ và cung cấp dịch vu: tạo ra hệ thống có khả năng hỗ trợ (bao gồm cả tư vấn và hướng dẫn) và cung cấp dịch vụ tiện ích, kết nối doanh nghiệp khởi nghiệp với các bên liên quan. Trong những năm gần đây, nền tảng, mạng lưới tư vấn và các không gian làm việc chung đã tăng về số lượng. Chúng hoạt động song song với các tổ chức truyền thống trong hỗ trợ doanh nghiệp khởi nghiệp như các vườn ươm, các doanh nghiệp gia tốc. Các nền tảng mới để tạo điều kiện liên kết giữa các công ty lớn và doanh nghiệp khởi nghiệp. Bên cạnh đó, các tổ chức trung gian về chuyển giao công nghệ, chuyển giao quyền sở hữu trí tuệ hay các tổ chức cung cấp dịch vụ pháp lý khác cùng tạo nên một mạng lưới liên kêt và hỗ trợ cho doanh nghiệp khởi nghiệp.

4.2.3. Nhóm tiêu chí đánh giá khả năng kết nối các thành phần trong hệ sinh thái khởi nghiệp
Trước hết, chính sách thúc đẩy khởi nghiệp cần tạo điều kiện để hình thành các phần tử trong hệ sinh thái, tiếp đó là tạo cơ hội gặp gỡ, liên kết giữa các phần tử thông qua việc cung cấp nền tảng pháp lý và hạ tầng, đặc biệt là hạ tầng công nghệ thông tin.

4.2.4. Nhóm tiêu chi đánh giá khả năng không tạo ra các rào cản pháp lý và hành chính cho khởi nghiệp

Rào cản pháp lý và hành chính thường được đánh giá là rào cản lớn trong quá trình hình thành và phát triển doanh nghiệp nói chung. Chính sách thúc đẩy khởi nghiệp cần tháo gỡ các rào cản này. Các thủ tục từ lúc thành lập tới thoái vốn cũng như các thủ tục tiếp cận các nguồn lực như tài chính, hỗ trợ,... cần được thúc đẩy nhanh chóng tương tích với nhu cầu và khả năng tăng trưởng nhanh của doanh nghiệp khởi nghiệp.

4.2.5. Nhóm tiêu chí đánh giá khả năng hỗ trọ doanh nghiệp khởi nghiệp hội nhập thị truòng quốc tế

Chính sách thúc đẩy khởi nghiệp không thể không cung cấp các điều kiện thuận lợi để doanh nghiệp khởi nghiệp đạt mục tiêu toàn cầu hóa của mình. Chính sách có thể đạt được điều này thông qua việc tạo điều kiện để doanh nghiệp khởi nghiệp tiếp cân các nguồn lục tù bên ngoài quốc gia (tài chính, KH\&CN, nhân lực, ...), tiếp cận thị trường quốc tế, định hướng và hỗ trợ doanh nghiệp khởi nghiệp tiệm cận các tiêu chuẩn quốc tế cũng như tạo nguồn lực cạnh tranh tù quốc tế thông qua các cấp phép đối với doanh nghiệp khởi nghiệp từ nước ngoài vào trong nước (ví dụ: visa cho doanh nghiệp khởi nghiệp, ưu đãi đối với các doanh nghiệp khởi nghiệp từ nước ngoài,...).

4.3. Khung đánh giá và cách thức tiến hành đánh giá

\subsubsection{Khung đánh giá}

Trên cơ sở các tiêu chí lớn được đưa ra ở trên, sau đây là hệ tiêu chí cụ thể được thể hiện trong khung đánh giá. 
Bảng 2. Khung đánh giá chính sách thúc đẩy khởi nghiệp trong bối cảnh toàn cầu hóa (Nguồn: Tác giả)

\begin{tabular}{|c|c|c|c|c|}
\hline $\begin{array}{l}\text { Nhóm } \\
\text { tiêu } \\
\text { chí }\end{array}$ & $\begin{array}{l}\text { Mục } \\
\text { tiêu/Tiêu } \\
\text { chí } \\
\text { đánh giá }\end{array}$ & $\begin{array}{l}\text { Loại chính } \\
\text { sách được } \\
\text { xem xét }\end{array}$ & $\begin{array}{l}\text { Hành động của chính } \\
\text { sách được đo lường }\end{array}$ & Chỉ số \\
\hline \multirow[t]{9}{*}{1} & \multirow[t]{9}{*}{$\begin{array}{l}\text { Khả } \\
\text { năng } \\
\text { khích lệ̀ } \\
\text { tinh thần } \\
\text { sáng tạo } \\
\text { và tinh } \\
\text { thần } \\
\text { kinh } \\
\text { thương }\end{array}$} & \multirow[t]{3}{*}{$\begin{array}{l}\text { Chính sách } \\
\text { giáo dục và } \\
\text { đào tạo }\end{array}$} & $\begin{array}{l}\text { Thay đổi nhận thức của } \\
\text { người học thông qua } \\
\text { chương trình đào tạo với } \\
\text { các môn học môn học về } \\
\text { đổi mới và kinh doanh } \\
\text { (Innovation \& } \\
\text { Entrepreuership) }\end{array}$ & $\begin{array}{l}\text { - Số lượng các trường trung học và đại học } \\
\text { có môn học về đổi mới và kinh doanh trong } \\
\text { chương trình đào tạo. } \\
\text { - Số lượng chương trình đào tạo chuyên sâu } \\
\text { về đổi mới và kinh doanh (được triển khai ở } \\
\text { cấp trung học, đại học, sau đại học và các } \\
\text { khóa đào tạo ngắn hạn do tổ chức khác triển } \\
\text { khai) }\end{array}$ \\
\hline & & & $\begin{array}{l}\text { Khích lệ tinh thần sáng } \\
\text { tạo thông qua việc thay } \\
\text { đổi tiêu chí đánh giá } \\
\text { trong giáo dục }\end{array}$ & $\begin{array}{l}\text { - Số lượng các trường trung học và đại học } \\
\text { có tiêu chí đánh giá về sáng tạo trong đánh } \\
\text { giá người học }\end{array}$ \\
\hline & & & $\begin{array}{l}\text { Khích lệ tinh thần kinh } \\
\text { thương thông qua các } \\
\text { hoạt động đầu tư/hỗ trợ } \\
\text { (tài chính và phi tài } \\
\text { chính) cho người học } \\
\text { khởi nghiệp }\end{array}$ & $\begin{array}{l}\text { - Số lượng các trường trung học và đại học } \\
\text { có hoạt động đầu tư/hồ trợ (tài chính và phi } \\
\text { tài chính) cho người học khởi nghiệp }\end{array}$ \\
\hline & & \multirow[t]{6}{*}{$\begin{array}{l}\text { Chính sách } \\
\text { nghiên cứu } \\
\text { khoa học }\end{array}$} & $\begin{array}{l}\text { Khích lệ sáng tạo thông } \\
\text { qua các chính } \\
\text { sách/chương trình } \\
\text { khuyến khích và hỗ trợ } \\
\text { nghiên cứu khoa học của } \\
\text { Nhà nước }\end{array}$ & $\begin{array}{l}\text { - Các biện pháp khuyến khích và hỗ trợ } \\
\text { nghiên cứu khoa học của Nhà nước }\end{array}$ \\
\hline & & & \multirow{4}{*}{$\begin{array}{l}\text { Khích lệ sáng tạo thông } \\
\text { qua việc thúc đẩy nghiên } \\
\text { cứu khoa học trong môi } \\
\text { trường giáo dục }\end{array}$} & $\begin{array}{l}\text { - Số lượng các trường trung học và đại học } \\
\text { có quy định về nghiên cứu khoa học đối với } \\
\text { người học trong thời gian theo học }\end{array}$ \\
\hline & & & & $\begin{array}{l}\text { - Số lượng các trường trung học và đại học } \\
\text { có chính sách khuyến khích người học } \\
\text { nghiên cứu khoa học (các hình thức khen } \\
\text { thưởng/cộng điểm/đầu tu cho nghiên cúu,...) }\end{array}$ \\
\hline & & & & $\begin{array}{l}\text { - Số lượng các trường trung học, trường đại } \\
\text { học có cơ sở vật chất dành cho nghiên cứu } \\
\text { khoa học (phòng thí nghiệm, không gian } \\
\text { sáng tạo,...) }\end{array}$ \\
\hline & & & & $\begin{array}{l}\text { - Số lượng sáng chế đăng ký và bảo hộ } \\
\text { quyền sở hữu trí tuệ bởi các trường trung } \\
\text { học và trường đại học }\end{array}$ \\
\hline & & & $\begin{array}{l}\text { Định hướng sáng tạo } \\
\text { trong các lĩnh vực mũi } \\
\text { nhọn/ưu tiên }\end{array}$ & $\begin{array}{l}\text { - Các định hướng và giải pháp thúc đẩy sáng } \\
\text { tạo trong các lĩnh vực mũi nhọn/ưu tiên }\end{array}$ \\
\hline
\end{tabular}


Chính sách thương mại hóa kết quả nghiên cứu

Chính sách văn hóa khởi nghiệp
Khích lệ gắn kết sáng tạo với thương mại hóa kết quả nghiên cứu

Hình thành các bên trung gian kết nối khu vực nghiên cứu - thị trường
- Các biện pháp định hướng nghiên cứu mang tính ứng dụng cao

- Các ưu đãi trong chuyển giao và ứng dụng kết quả nghiên cứu

- Các quy định đảm bảo quyền sở hữu trí tuệ trong thương mại hóa kết quả nghiên cứu

- Các hoạt động tư vấn, hỗ trợ/ dịch vụ khai thác thông tin khoa học \& công nghệ và thông tin thị trường dành cho các nhà nghiên cứu (xã hội hóa thông tin sở hữu công nghiệp, lập biểu đồ sáng chế, biểu đồ $n h u$ cầu thị trường,...)

- Cơ sở hạ tầng hỗ trợ chuyển giao kết quả nghiên cứu (sàn giao dịch ý tưởng, sàn giao dịch công nghệ, các trung tâm hồ trợ chuyển giao, bộ phận tur vấn về sở hũu trí tuệ dành cho đối tuợng đang có nhu cầu khởi nghiệp,...)

- Số lượng trường trung học, trường đại học có các đơn vị giúp tư vấn và thương mại hóa kết quả nghiên cứu (có phòng $R \& D$, doanh nghiệp khởi nguồn - spin-off, trung tâm chuyển giao công nghệ - TTO, trung tâm chuyển giao quyền sở hũu trí tuê - TLO,...)

- Số lượng ý tưởng sáng tạo/sáng chế được thương mại hóa từ các trường trung học, trường đại học và ngoài trường đại học

Nâng cao nhận thức về văn hoá kinh doanh thông qua các chương trình, hoạt động (sụ kiện, giải thuớng, cuộc thi,...)

Hình thành văn hóa khởi nghiệp thông qua các chương trình và hoạt động khởi nghiệp

- Số lượng các trường trung học và đại học tổ chức các hoạt động (sụ kiện, giải thưởng, $c u \hat{c} c$ thi,...) nhằm nâng cao nhận thức về văn hoá kinh doanh

- Các chương trình và hoạt động nhằm nâng cao nhận thức về văn hoá kinh doanh của các tổ chức khác

- Các chương trình và hoạt động nhằm hình thành văn hóa khởi nghiệp trong và ngoài các nhà trường

- Số lượng các Vườn ươm (Incubator) và Tổ chức thúc đẩy kinh doanh (Accelerator) đang hoạt động ở Việt Nam

- Số lượng các startup được ươm thành công thông qua các vườn ươm và các Tổ chức thúc đẩy kinh doanh

- Uu đãi dành cho vườn ươm và các tổ chức thúc đẩy kinh doanh trong hoạt động ươm tạo startup 


$\begin{array}{ll}\text { Chính sách } & \begin{array}{l}\text { Hình thành các nguồn } \\ \text { tâi chính } \\ \text { vòn dành cho doanh } \\ \text { nghiệp khởi nghiệp }\end{array}\end{array}$

Chính sách thông tin

Chính sách thị trường

Chính sách về hệ thống hỗ trợ và cung cấp dịch vụ

Khả năng kết nối các thành phần trong hệ sinh thái khởi nghiệp
Chính sách phát triển hệ sinh thái khởi nghiệp
- Các loại vốn doanh nghiệp khởi nghiệp có thể tiếp cận (Vốn mồi (Seed capital), Vốn cộng đồng (Crowdfunding), đâu tu mạo hiếm (Venture capital), đầu tu thiên thần (Angel investors), tín dụng,...)

- Số lượng các tổ chức (nhà nước/phi nhà nuớc, nước ngoài/Việt Nam) cung cấp tài chính phi truyền thống dành cho doanh nghiệp khởi nghiệp

- Số lượng doanh nghiệp khởi nghiệp được nhận đầu tư và chất lượng đầu tư
Thúc đẩy tài chính cho doanh nghiệp khởi nghiệp từ khu vực công và tư, từ khu vực trong và ngoài nước

Uu đãi đặc biệt về tài chính dành cho đối tượng khởi nghiệp

- Biện pháp thu hút các nhà đầu tư khởi nghiệp

- Các ưu đãi dành cho các nhà đầu tư khởi nghiệp

- Các ưu đãi thuế, các ưu đãi trong vay thương mại,...dành cho đối tượng khởi nghiệp

- Khả năng tiếp cận thông tin về khoa học và công nghệ trạng thông tin bất đối xứng của doanh nghiệp khởi nghiệp

Hình thành thị trường cho khởi nghiệp

- Khả năng tiếp cận thông tin về các nhà đầu tư

- Khả năng tiếp cận thông tin về thị trường

- Khả năng tiếp cận thông tin về các chương trình hỗ trợ/ưu đãi của nhà nước

- Các điều kiện đảm bảo thị trường cạnh tranh lành mạnh

- Các động thái của chính phủ trong việc kích hoạt nhu cầu thị trường cho doanh nghiệp khởi nghiệp

Hình thành mạng lưới hỗ trợ và cung cấp dịch vụ cho doanh nghiệp khởi nghiệp

- Khung khổ pháp lý thuận lợi cho việc hình thành và hoạt động của các tổ chức hồ trợ, cung cấp dịch vụ cho khởi nghiệp

- Mạng lưới hướng dẫn, hỗ trợ và cung cấp dịch vụ cho khởi nghiệp: TLO, TTO, Coworking space,,..

- Mạng lưới và sự phối hợp giữa các thành

Tạo điều kiện để hình thành và liên kết các tố trong hệ sinh thái phần tử trong hệ sinh thái

(nền tảng pháp lý và hạ tầng) 


\begin{tabular}{|c|c|c|c|c|}
\hline \multirow[t]{3}{*}{4} & \multirow{3}{*}{$\begin{array}{l}\text { Khả } \\
\text { năng } \\
\text { không } \\
\text { tạo ra } \\
\text { các rào } \\
\text { cản pháp } \\
\text { lý và } \\
\text { hành } \\
\text { chính } \\
\text { cho khởi } \\
\text { nghiệp }\end{array}$} & \multirow[t]{3}{*}{$\begin{array}{l}\text { Các cải cách } \\
\text { thủ tục hành } \\
\text { chính đối với } \\
\text { doanh nghiệp } \\
\text { khởi nghiệp }\end{array}$} & $\begin{array}{l}\text { Cơ sở pháp lý và hạ tầng } \\
\text { cho việc tiến hành các } \\
\text { thủ tục đối với doanh } \\
\text { nghiệp khởi nghiệp }\end{array}$ & $\begin{array}{l}\text { - Khung pháp lý về thủ tục thành lập, mở } \\
\text { rộng và chấm dứt kinh doanh đối với doanh } \\
\text { nghiệp khởi nghiệp } \\
\text { - Bộ phận tư vấn và hỗ trợ doanh nghiệp } \\
\text { khởi nghiệp tiến hành các thủ tục pháp lý }\end{array}$ \\
\hline & & & \multirow{2}{*}{$\begin{array}{l}\text { Tạo thuận lợi cho doanh } \\
\text { nghiệp khởi trong trong } \\
\text { tiến hành các thủ tục } \\
\text { pháp lý }\end{array}$} & $\begin{array}{l}\text { - Sự thuận lợi trong thủ tục thành lập, mở } \\
\text { rộng và chấm dứt kinh doanh đối với doanh } \\
\text { nghiệp khởi nghiệp }\end{array}$ \\
\hline & & & & $\begin{array}{l}\text { - Sự thuận lợi trong các thủ tục khác như } \\
\text { vay vôn, tiếp cận các ưu đãi,... đối với } \\
\text { doanh nghiệp khởi nghiệp }\end{array}$ \\
\hline \multirow[t]{5}{*}{5} & \multirow{5}{*}{$\begin{array}{l}\text { Khả } \\
\text { năng hỗ } \\
\text { trợ } \\
\text { doanh } \\
\text { nghiệp } \\
\text { khởi } \\
\text { nghiệp } \\
\text { hội nhập } \\
\text { thị } \\
\text { trường } \\
\text { quốc tế }\end{array}$} & \multirow[t]{5}{*}{$\begin{array}{l}\text { Chính sách } \\
\text { hội nhập cho } \\
\text { khơoi nghiệp }\end{array}$} & \multirow[t]{3}{*}{$\begin{array}{l}\text { Hỗ trợ doanh nghiệp } \\
\text { khởi nghiệp mớ rộng ra } \\
\text { thị trường quốc tế }\end{array}$} & $\begin{array}{l}\text { - Các điều kiện thuận lợi được tạo ra để } \\
\text { doanh nghiệp khởi nghiệp tiếp cận các } \\
\text { nguồn lực từ bên ngoài quốc gia (tài chính, } \\
K H \& C N, \text { nhân lưc,...) }\end{array}$ \\
\hline & & & & $\begin{array}{l}\text { - Các điều kiện thuận lợi được tạo ra để } \\
\text { doanh nghiệp khởi nghiệp tiếp cận thị } \\
\text { trường quốc tế }\end{array}$ \\
\hline & & & & $\begin{array}{l}\text { - Các định hướng và hỗ trợ doanh nghiệp } \\
\text { khởi nghiệp tiệm cận các tiêu chuấn quốc tế }\end{array}$ \\
\hline & & & \multirow{2}{*}{$\begin{array}{l}\text { Tạo thuận lợi cho doanh } \\
\text { nghiệp khời nghiệp từ } \\
\text { nước ngoài vào quốc gia }\end{array}$} & $\begin{array}{l}\text { - Cấp Visa đặc biệt cho doanh nghiệp khởi } \\
\text { nghiệp }\end{array}$ \\
\hline & & & & $\begin{array}{l}\text { - Các ưu đãi khác đối với các doanh nghiệp } \\
\text { khởi nghiệp từ nước ngoài vào Việt Nam }\end{array}$ \\
\hline
\end{tabular}

\subsubsection{Cách thức triển khai khung đánh giá}

Phụ thuộc vào mục tiêu đánh giá, có thể lựa chọn đánh giá theo các cách thức khác nhau với khung đánh giá như trên. Các chỉ số này cần thống kê trước khi ban hành chính sách và đánh giá tác động của chính sách (trước và sau khi ban hành). Sau đây, tác giả xin chỉ ra hai bước đánh giá với hai mức độ: đánh giá tổng quát và đánh giá cu thể các tác động.

\section{1. Đánh giá tổng quát}

Ở mức độ này, công việc đánh giá đơn thuần là đánh giá mức độ tồn tại và hoạt động của chính sách. Có thể đánh giá chính sách thúc đẩy khởi nghiệp bằng cách đưa ra những đánh dấu được mã hóa như dưới đây thông qua việc xem xét từng chính sách cụ thể:

Bảng 3. Khung đánh giá mức độ hoạt động của chính sách thúc đẩy khởi nghiệp

$$
\text { (Nguồn: Tác giả) }
$$

\begin{tabular}{cccc} 
Hoạt động & Không hoạt động & Vừa được tạo ra \\
\hline $\begin{array}{c}\text { Nhóm } \\
\text { tiêu } \\
\text { chí }\end{array}$ & $\begin{array}{c}\text { Mục tiểu/ } \\
\text { Tiêu chí đánh giá }\end{array}$ & $\begin{array}{c}\text { Mức độa chính sách được xem xét } \\
\text { hoạt động }\end{array}$ \\
\hline $\mathbf{1}$ & $\begin{array}{l}\text { Khả năng khích lệ tinh thần } \\
\text { sáng tạo và tinh thần kinh } \\
\text { thương }\end{array}$ & $\begin{array}{l}\text { Chính sách giáo dục và đào tạo } \\
\text { Chính sách nghiên cứu khoa học } \\
\text { Chính sách thương mại hóa kết quả nghiên cứu }\end{array}$ \\
\hline
\end{tabular}




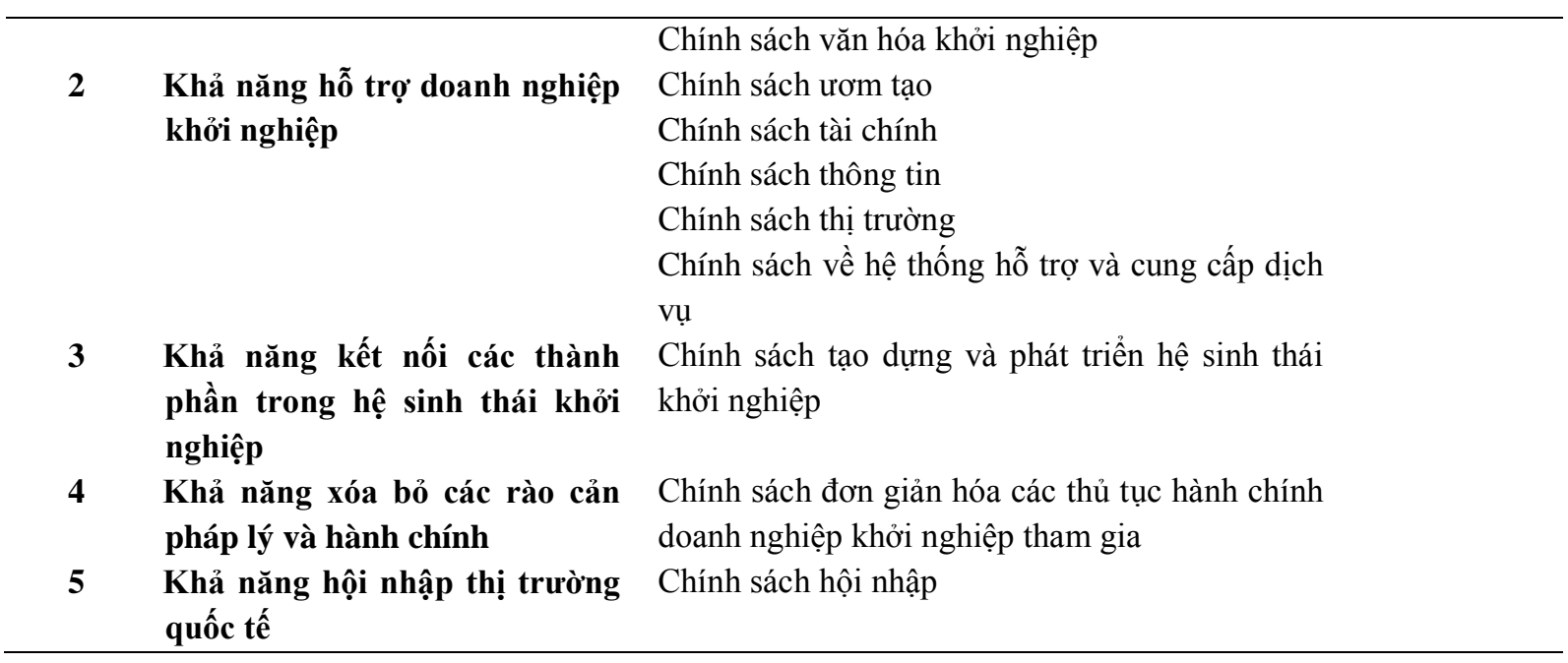

Hoàn toàn có thể áp dụng khung đánh giá này để tiếp tục so sánh mức độ hoạt động của chính sách thúc đẩy khởi nghiệp ở từng lĩnh vực/địa phương cụ thể với cách thực hiện tương tự như trên.

Bảng 4. Khung đánh giá mức độ hoạt động của chính sách thúc đẩy khởi nghiệp theo lĩnh vực/địa phương

(Nguồn: Tác giả)

\begin{tabular}{|c|c|c|c|c|}
\hline $\begin{array}{l}\text { Nhóm } \\
\text { tiêu } \\
\text { chí }\end{array}$ & $\begin{array}{l}\text { Mục tiêu/ } \\
\text { Tiêu chí đánh } \\
\text { giá }\end{array}$ & $\begin{array}{l}\text { Loại } \\
\text { chính sách được xem xét }\end{array}$ & $\begin{array}{l}\text { Lĩnh vực/ } \\
\text { Địa phương } \\
1\end{array}$ & $\begin{array}{l}\text { Lĩnh vực/ } \\
\text { Địa phương } \\
2\end{array}$ \\
\hline 1 & $\begin{array}{l}\text { Khả năng khích } \\
\text { lệ tinh thẩn sáng } \\
\text { tạo và tinh thần } \\
\text { kinh thương }\end{array}$ & $\begin{array}{l}\text { Chính sách giáo dục và đào tạo } \\
\text { Chính sách nghiên cứu khoa học } \\
\text { Chính sách thương mại hóa kêt quả nghiên } \\
\text { cứu } \\
\text { Chính sách văn hóa khởi nghiệp }\end{array}$ & & \\
\hline 2 & $\begin{array}{l}\text { Khả năng hỗ trợ } \\
\text { doanh nghiệp } \\
\text { khởi nghiệp }\end{array}$ & $\begin{array}{l}\text { Chính sách ươm tạo } \\
\text { Chính sách tài chính } \\
\text { Chính sách thông tin } \\
\text { Chính sách thị trường } \\
\text { Chính sách về hệ thống hỗ trợ và cung cấp } \\
\text { dịch vụ }\end{array}$ & & \\
\hline 3 & $\begin{array}{l}\text { Khả năng kết } \\
\text { nối các thành } \\
\text { phần trong hệ } \\
\text { sinh thái khởi } \\
\text { nghiệp }\end{array}$ & $\begin{array}{l}\text { Chính sách tạo dựng và phát triển hệ sinh } \\
\text { thái khởi nghiệp }\end{array}$ & & \\
\hline 4 & $\begin{array}{l}\text { Khả năng không } \\
\text { tạo ra các rào } \\
\text { cản pháp lý và } \\
\text { hành chính cho } \\
\text { khởi nghiệp }\end{array}$ & $\begin{array}{l}\text { Các cải cách thủ tục hành chính đối với } \\
\text { doanh nghiệp khởi nghiệp }\end{array}$ & & \\
\hline 5 & Khả năng hỗ trợ & Chính sách hội nhập cho khởi nghiệp & & \\
\hline
\end{tabular}


doanh nghiệp

khởi nghiệp hội

nhập thị trường

quốc tế

2) Đánh giá tác động của chính sách

Ở mức độ đánh giá này, đòi hỏi xem xét cụ thể các tác động của chính sách, từ đó đánh giá về việc đạt mục tiêu thúc đẩy khởi nghiệp của chính sách.

Để thuận lợi cho việc so sánh và đánh giá các tác động của chính sách có thể sử dụng một thang đo 7 điểm của khung đánh giá (PAF) như sau để áp dụng cho việc đánh giá từng mục tiêu của chính sách hay từng chính sách thành phần. Điểm số của các lựa chọn này là kết quả phỏng vấn các đối tượng liên quan/chuyên gia, áp dụng với các tiêu chí đánh giá đã đưa ra trong khung đánh giá:

Bảng 5. Khung đánh giá tác động của chính sách theo thang đo 7 điểm

(Nguồn: Tác giả)

\begin{tabular}{c|c|c|c|c|c|c}
\hline-3 & -2 & -1 & 0 & +1 & +2 & +3 \\
\hline $\begin{array}{c}\text { Tác động } \\
\text { tiêu cực } \\
\text { mạnh }\end{array}$ & $\begin{array}{c}\text { Tác động } \\
\text { tiêu cực } \\
\text { vừa phải }\end{array}$ & $\begin{array}{c}\text { Tác động } \\
\text { tiêu cực } \\
\text { nhẹ }\end{array}$ & $\begin{array}{c}\text { Tác động } \\
\text { trung tính }\end{array}$ & $\begin{array}{c}\text { Tác động } \\
\text { tích cực } \\
\text { nhẹ }\end{array}$ & $\begin{array}{c}\text { Tác động } \\
\text { tích cực } \\
\text { vừa phải }\end{array}$ & $\begin{array}{c}\text { Tác động } \\
\text { tích cực } \\
\text { mạnh }\end{array}$
\end{tabular}

\begin{tabular}{|c|c|c|c|}
\hline $\begin{array}{l}\text { Nhóm } \\
\text { tiêu chí }\end{array}$ & $\begin{array}{l}\text { Mục tiêu/Tiêu chí } \\
\text { đánh giá }\end{array}$ & Loại chính sách được xem xét & $\begin{array}{l}\text { Lựa chọn mức } \\
\text { độ tác động }\end{array}$ \\
\hline 1 & $\begin{array}{l}\text { Khả năng khích lệ tinh thần } \\
\text { sáng tạo và tinh thần kinh } \\
\text { thương }\end{array}$ & $\begin{array}{l}\text { Chính sách giáo dục và đào tạo } \\
\text { Chính sách nghiên cứu khoa học } \\
\text { Chính sách thương mại hóa kết quả nghiên cứu } \\
\text { Chính sách văn hóa khởi nghiệp }\end{array}$ & \\
\hline 2 & $\begin{array}{l}\text { Khả năng hỗ trợ doanh } \\
\text { nghiệp khởi nghiệp }\end{array}$ & $\begin{array}{l}\text { Chính sách ươm tạo } \\
\text { Chính sách tài chính } \\
\text { Chính sách thông tin } \\
\text { Chính sách thị trường } \\
\text { Chính sách về hệ thống hỗ trợ và cung cấp dịch } \\
\text { vụ }\end{array}$ & \\
\hline 3 & $\begin{array}{l}\text { Khả năng kết nối các thành } \\
\text { phần trong hệ sinh thái khởi } \\
\text { nghiệp }\end{array}$ & $\begin{array}{l}\text { Chính sách tạo dựng và phát triển hệ sinh thái } \\
\text { khởi nghiệp }\end{array}$ & \\
\hline 4 & $\begin{array}{l}\text { Khả năng không tạo ra các } \\
\text { rào cản pháp lý và hành } \\
\text { chính cho khởi nghiệp }\end{array}$ & $\begin{array}{l}\text { Các cải cách thủ tục hành chính đối với doanh } \\
\text { nghiệp khởi nghiệp }\end{array}$ & \\
\hline 5 & $\begin{array}{l}\text { Khả năng hỗ trợ doanh } \\
\text { nghiệp khởi nghiệp hội nhập } \\
\text { thị trường quốc tế }\end{array}$ & Chính sách hội nhập cho khởi nghiệp & \\
\hline
\end{tabular}


Điểm số của các lựa chọn từ việc tiến hành khung đánh giá sau đó sẽ được trình bày trong sơ đồ mạng nhện. Các sơ đồ này đã được thiết kế để cho phép nhanh chóng so sánh và đánh giá các lựa chọn có thể bổ sung cho quá trình ra quyết định. Các biểu đồ được thể hiện theo dạng dưới đây:

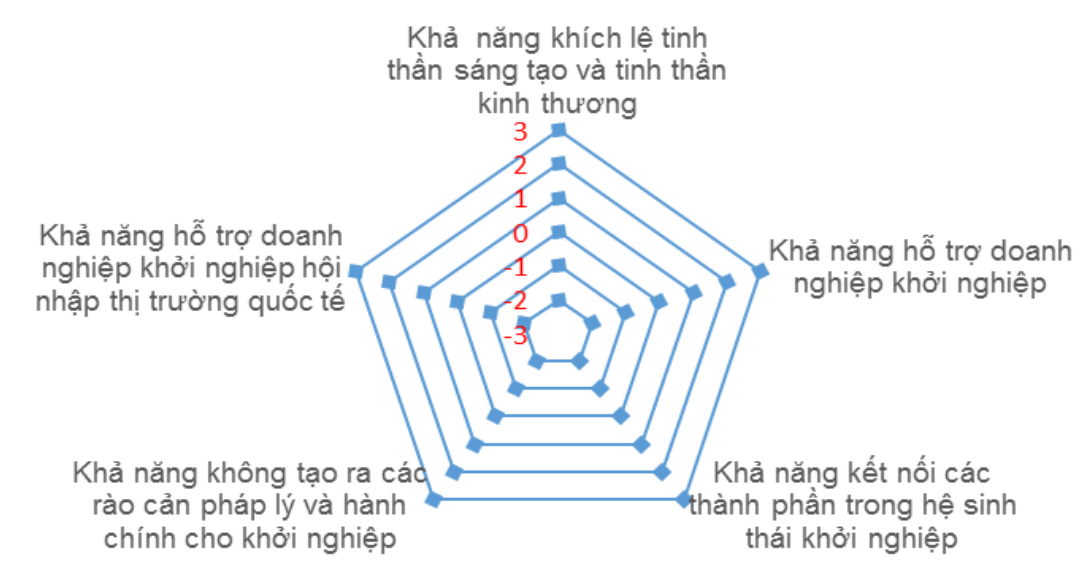

Hình 8. Kết quả đầu ra so với các mục tiêu của chính sách với thang đo 7 điểm

(Nguồn: Tác giả)

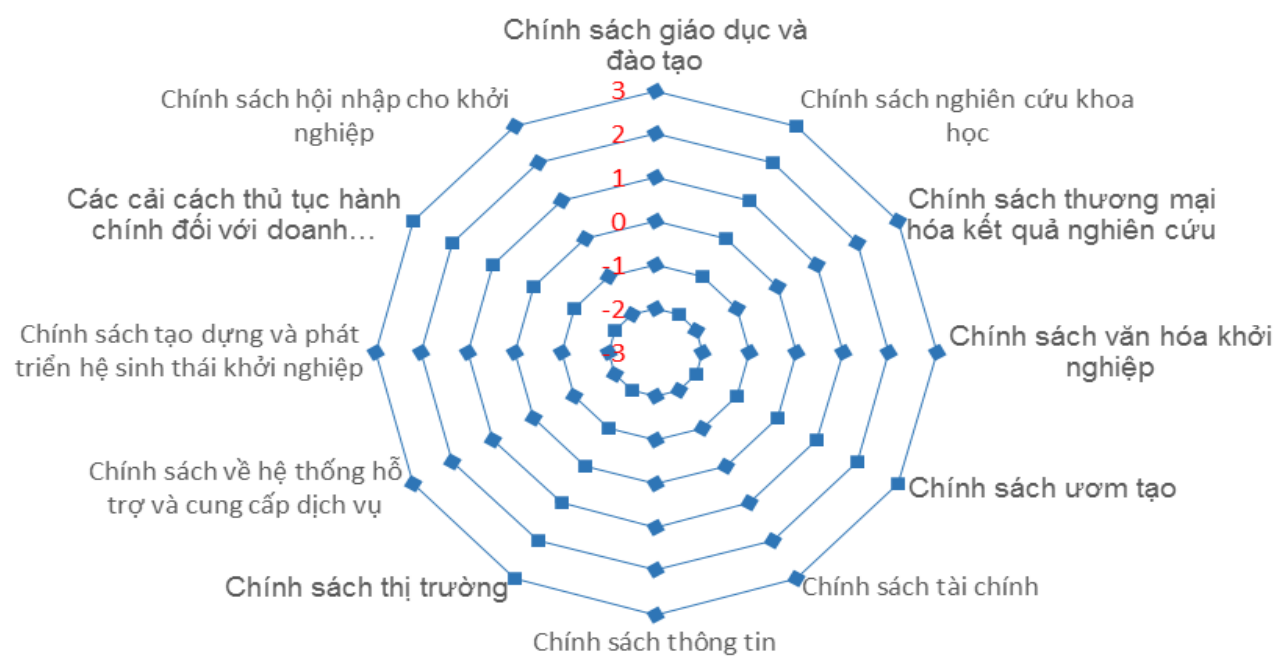


Ở mức độ đánh giá này, cũng hoàn toàn có thể áp dụng đánh giá đối với từng lĩnh vực/địa phương cụ thể để có sự so sánh giữa các lĩnh vực/địa phương. Ví dụ một kết quả đánh giá giữa hai địa phương theo 5 nhóm tiêu chí đã đưa ra:

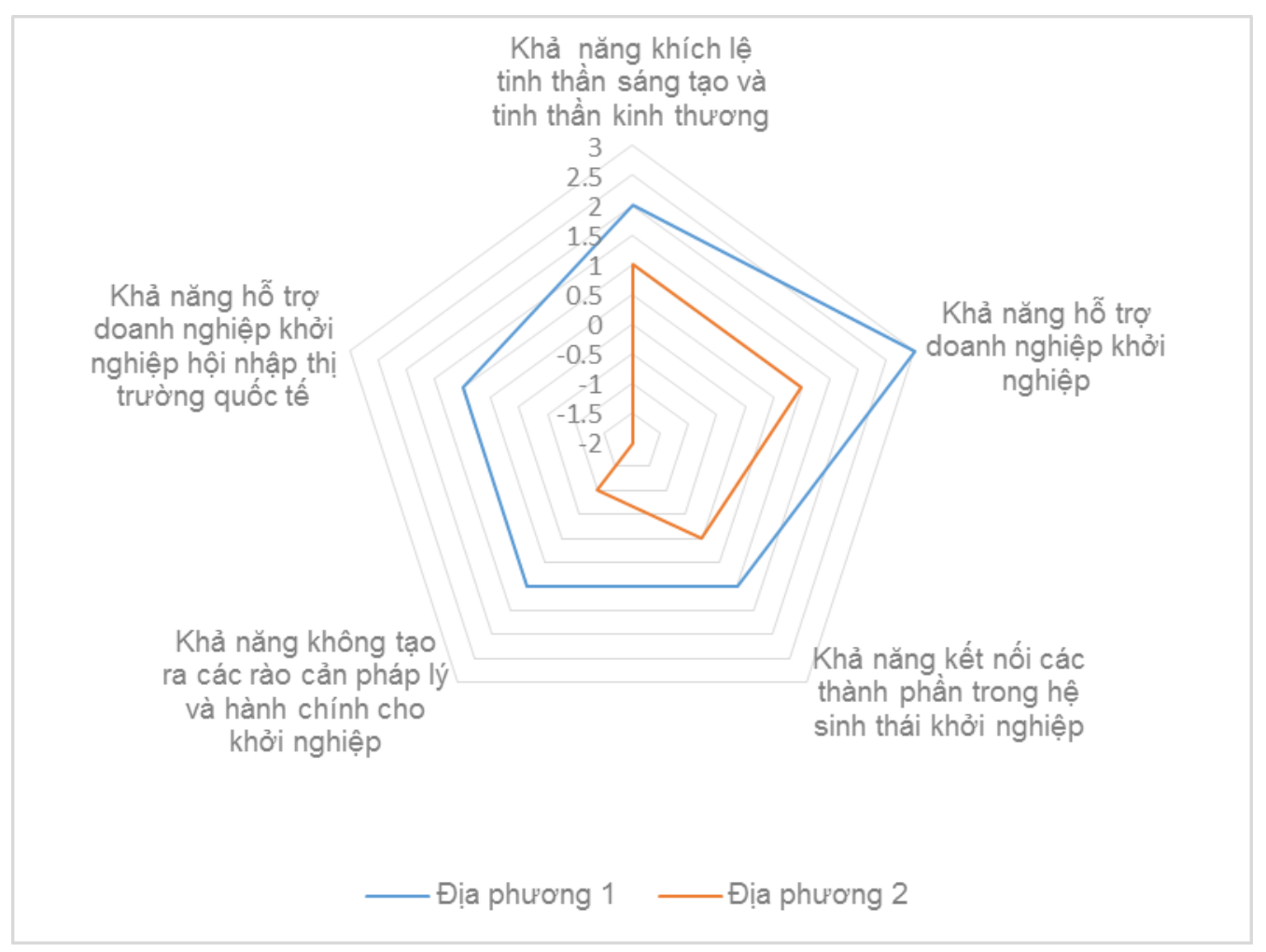

Hình 9. Kết quả đầu ra so với các mục tiêu của chính sách với thang đo 7 điểm so sánh giữa hai địa phương (Nguồn: Tác giả)

\section{Tổng kết}

Như vậy, khởi nghiệp (sáng tạo) là một hoạt động đặc biệt, với các đặc điểm khác với hoạt động kinh doanh thông thường như: tính đột phá (tính sáng tạo), tính rủi ro cao, quy mô linh hoạt, tăng trưởng nhanh định hướng quy mô toàn cầu và có văn hóa tổ chức riêng biệt (mạo hiểm, đam mê kinh doanh, sáng tạo,...), đòi hỏi các yêu cầu riêng biệt trong chính sách thúc đẩy.

Việc đánh giá chính sách thúc đẩy khởi nghiệp trong bối cảnh toàn cầu hóa cần cần được tiến hành thường xuyên nhằm chỉ ra các hạn chế trong việc đạt mục tiêu của chính sách và đề xuất các phương án điều chỉnh, hoàn thiện chính sách. Hoạt động đánh giá này cần chú trọng tới 5 nhóm tiêu chí cốt lõi thể hiện đặc trưng/yêu cầu cần có của chính sách thúc đẩy khởi nghiệp trong bối cảnh toàn cầu hóa:

1) Nhóm tiêu chí đánh giá khích lệ tinh thần sáng tạo và tinh thần kinh thương.

2) Nhóm tiêu chí đánh giá khả năng hỗ trợ doanh nghiệp khởi nghiệp (ươm tạo, tài chính, thông tin, tư vấn và hướng dẫn, dịch vụ hỗ trợ, ...).

3) Nhóm tiêu chí đánh giá khả năng kết nối các thành phần trong hệ sinh thái khởi nghiệp. 
4) Nhóm tiêu chí đánh giá khả năng không tạo ra các rào cản pháp lý và hành chính cho khởi nghiệp.

5) Nhóm tiêu chí đánh giá khả năng hỗ trợ doanh nghiệp khởi nghiệp hội nhập thị trường quốc tế.

\section{Tài liệu trích dẫn}

[1] OECD and Eurostat, Oslo Manual - Guidelines for Collecting and Interpreting Innovation Data, Paris: OECD, 2005

[2] Essegbey G., Ghana: Cassava, cocoa and poultry, In: Larsen K, Kim R and Theus F, eds. Agribusiness and Innovation Systems in Africa. World Bank. Washington D.C., 2008

[3] Jongtaik Lee, Jeongsik Lee, Byungcheol Kim và Yun Jeong Choi, Study for Roles of Major Players in Technology Commercialization Processes and their Case Studies. International Journal of $\mathrm{u}$ - and e- Service, Science and Technology Vol.9, No. 2 (2016), pp.363-374

[4] Marotti de Mello, Adriana; Demonel de Lima, Wander; Vilas Boas, Eduardo; Sbragia, Roberto; Marx, Roberto, Innovative Capacity and Competitive Advantage: a case study of Brazilian firms, RAI - Revista de Administração e Inovação, São Paulo, v. 5, n. 2, p. 57-72, 2008

[5] Startup AUS, Economy in Transition: Startups, innovation, and a workforce for the future, 2016

[6] Samir Rath, Teodora Georgieva, No Startup Hipsters: Build Scalable technology companies, 2014

[7] Website: http://www.startupcommons.org/customers.html

[8] Mason, C. \& Brown, R., Entrepreneurial Ecosystems and Growth Oriented Entrepreneurship, OECD, The Hague, 2014
[9] Isenberg, D., Entrepreneurship, Retrieved from Harvard Business Review: https://hbr.org/2014/05/what-an-entrepreneurialecosystem-actually-is, 2014

[10] Kevin H. O'Rourke, Jeffrey G. Williamson, Globalisation and History: The Evolution of a Nineteenth-century Atlantic Economy, MIT Press, 2001

[11] OECD, The Knowledge-based Economy, Paris: OECD, 1996

[12] Trung tâm nghiên cứu thương mại quốc tế về công nghệ, Viện Ngoại thương Ấn Độ, A Pilot Study on Technology based Start-ups, 2017

[13] Startup Genome LLC, Global Startup Ecosystem Report 2017, 2017

[14] Trung tâm nghiên cứu thương mại quốc tế về công nghệ, Viện Ngoại thương Ân Độ, A Pilot Study on Technology based Start-ups, 2017

[15] The World Bank, Innovation Policy: A Guide for Developing Countries, 2010

[16] Sarfraz A. Mian, Science and Technology Based Regional Entrepreneurship: Global Experience in Policy and Program Development. Edward Elgar Publishing, 2011

[17] Phạm Hồng Quất, Hệ sinh thái khởi nghiệp Việt Nam: Nhà nước làm đòn bẩy cho tư nhân, http://khoahocphattrien.vn/tin-tuc/he-sinh-thaikhoi-nghiep-viet-nam-nha-nuoc-lam-don-baycho-tu-nhan/20151029031158962p1c882.htm, 2015

[18] Vũ Cao Đàm, Trịnh Ngọc Thạch, Đào Thanh Trường, Kỹ năng đánh giá chính sách, Nxb Thế giới, Hà Nội, 2017

[19] OECD, Start-up Latin American 2016 building an Innovative Future - Assessment and Recommendations, 2016

[20] Phòng Thương mại và Công nghiệp Việt Nam, Báo cáo Chỉ số khởi nghiệp Việt Nam 2015/16 (GEM 2015/16), Nxb Giao thông vận tải, 2016 


\title{
Developing a Set of Criteria to Evaluate Startups Promoting Policies in the Context of Globalization
}

\author{
Hoang Thi Hai Yen \\ VNU University of Social Sciences and Humanities, 336 Nguyen Trai, Thanh Xuan, Hanoi, Vietnam
}

\begin{abstract}
The paper initially provides a theoretical basis based on the characteristics and requirements of the policy of promoting startup in the context of globalization, thereby developing a criteria system for evaluating this type of policy. The criteria stystem can be used to conduct a policy review that promotes startup in the context of globalization, apply to policy assessment in Vietnam and make suggestions for policy improvement.
\end{abstract}

Keywords: Startup, the policy of promoting startup, globalization, evaluation criteria system. 